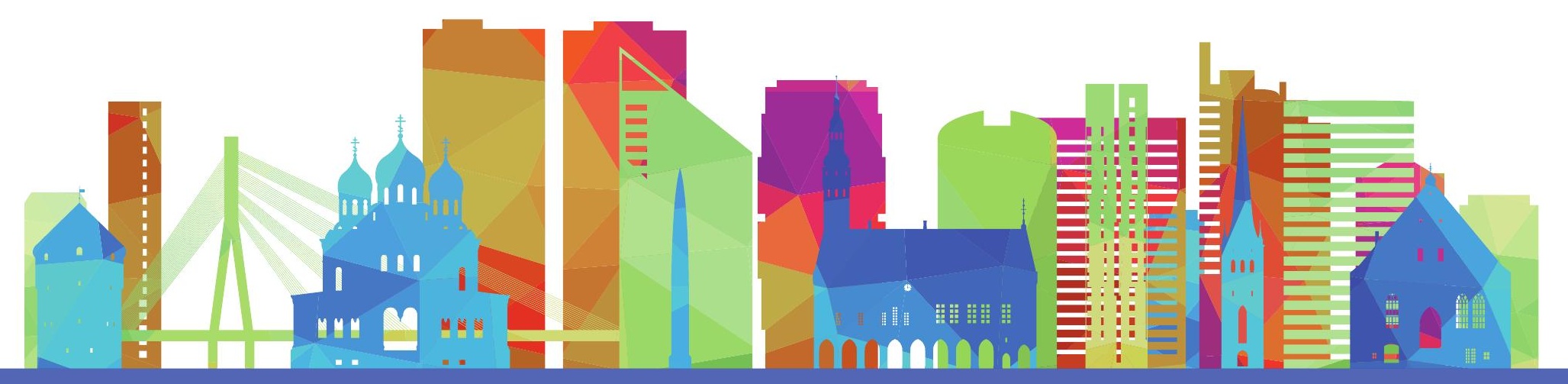

BOOSTING SOCIAL ENTREPRENEURSHIP

AND SOCIAL ENTERPRISE DEVELOPMENT

IN ESTONIA

In-depth Policy Review 


\title{
Boosting Social Entrepreneurship and Social Enterprise Development in Estonia
}

\author{
In-depth Policy Review
}

This report provides an in-depth analysis of the Estonian policy ecosystem in place for social innovation, social entrepreneurship and social enterprises. It identifies the country's key strengths and challenges and provides policy recommendations to support the development of a stronger policy ecosystem. Key policy issues analysed include: building a culture of social innovation and social entrepreneurship (Section 2); supporting social entrepreneurship and social enterprises through institutional and legal frameworks (Section 3); improving access to finance and to markets to boost social entrepreneurship and social enterprises (Sections 4 and 5); and supporting the development of social entrepreneurial skills and capacity (Section 6).

JEL codes: L31, L33

Key words: social entrepreneurship; social economy; social enterprises; social impact; social innovation; local development; policy ecosystem. 


\section{About the OECD}

The OECD is a unique forum where governments work together to address the economic, social and environmental challenges of globalisation. The OECD is also at the forefront of efforts to understand and to help governments respond to new developments and concerns, such as corporate governance, the information economy and the challenges of an ageing population. The Organisation provides a setting where governments can compare policy experiences, seek answers to common problems, identify good practice and work to co-ordinate domestic and international policies.

\section{About OECD Local Economic and Employment Development (LEED) Papers}

The OECD Local Economic and Employment Development (LEED) Programme Papers present innovative ideas and practical examples on how to boost local development and job creation. A wide range of topics are addressed, such as employment and skills; entrepreneurship; the social economy and social innovation; culture; and local capacity building, among others. The series highlights in particular policies to support disadvantaged places and people, such as the low skilled, the unemployed, migrants, youth and seniors.

This paper is published under the responsibility of the Secretary-General of the OECD. The opinions expressed and arguments employed herein do not necessarily reflect the official views of OECD member countries or the European Union.

This document as well as any statistical data and map included herein are without prejudice to the status of or sovereignty over any territory, to the delimitation of international frontiers and boundaries and to the name of any territory, city or area.

Authorised for publication by Lamia Kamal-Chaoui, Director of the Centre for Entrepreneurship, SMEs, Regions and Cities, OECD.

This document was produced with the financial support of the European Union. Its contents are the sole responsibility of the authors and do not necessarily reflect the views of the European Union.

\section{Please cite this publication as:}

OECD (2020), "Boosting Social Entrepreneurship and Social Enterprise Development in Estonia. In-depth Policy Review", OECD LEED Papers, 2020/02, OECD Publishing, Paris.

\section{Series: OECD LEED Papers}

Photos credits: @ Getty Images

\section{C) OECD 2020}

You can copy, download or print OECD content for your own use, and you can include excerpts from OECD publications, databases and multimedia products in your own documents, presentations, blogs, websites and teaching materials, provided that suitable acknowledgment of the source and copyright owner is given. All requests for public or commercial use and translation rights should be submitted to rights@oecd.org. 


\section{Acknowledgements}

This report was produced by the OECD Centre for Entrepreneurship, SMEs, Regions and Cities (CFE) led by Lamia Kamal-Chaoui, Director, as part of the Programme of Work of the Local Economic and Employment Development Programme. It was produced with the financial support of the DirectorateGeneral for Employment, Social Affairs and Inclusion of the European Commission. It is part of a series of in-depth policy reviews on "Boosting social entrepreneurship and social enterprise creation".

The report was prepared by Stellina Galitopoulou, Lou Aisenberg, Amal Chevreau, Elyssa Majed and Heejin Ahn in cooperation with and under the supervision of Antonella Noya, Head of Unit in the Local Employment, Skills and Social Innovation Division of CFE led by Karen Maguire, Acting Head. External experts also contributed, including by drafting parts of the report, namely Julie Simon and Gerhard Bräunling.

This report benefited from the valuable comments of the Directorate-General for Employment, Social Affairs and Inclusion of the European Commission, notably Risto Raivio and Estelle Bacconnier.

The OECD Secretariat is also grateful for the support and comments provided by counterparts, notably Marten Lauri and Kersti Ringmets from the Ministry of the Interior of Estonia.

Finally, the authors acknowledge François Iglesias for preparing the cover for this report. 


\section{Table of contents}

Acknowledgements 3

Acronyms 5

$\begin{array}{ll}\text { Executive summary } & 7\end{array}$

$\begin{array}{ll}\text { Action plan } & 10\end{array}$

1. The socio-economic and political context 15

2. Building a culture of social innovation and social entrepreneurship 21

3. Supporting social entrepreneurship and social enterprises through institutional and $\begin{array}{ll}\text { legal frameworks } & 29\end{array}$

4. Improving access to finance to boost social entrepreneurship and social enterprises

5. Improving access to markets to promote social entrepreneurship and social enterprises

6. Building capacity and developing social entrepreneurial skills 57

$\begin{array}{ll}\text { References } & 67\end{array}$

Annex 1.A. Key features, opportunities and challenges of social enterprises under different legal forms in Estonia

\section{FIGURES}

Figure 1. Investment spectrum

\section{TABLES}

Table 1. Strategic plans relevant to social entrepreneurship 


\section{Acronyms}

ASD

B2B

B2C

BIF

CSR

EaSI

EAFRD

EC

EFSI

EIF

EPVA

ERDF

ESEN

ESF

ESIF

ESTVCA

EU

FASE

3Fs

GCSLA

GECES

GDF

GDP

GIIN

GPP

IT

MEAT
Autism Spectrum Disorder

Business-to-Business

Business-to-Consumer

Baltic Innovation Fund

Corporate Social Responsibility

European Programme for Employment and Social Innovation

European Agricultural Fund for Rural Development

European Commission

European Fund for Strategic Investments

European Investment Fund

European Venture Philanthropy Association

European Regional Development Fund

Estonian Social Enterprise Network

European Social Fund

European Structural and Investment Funds

Estonian Private Equity and Venture Capital Association

European Union

Financing Agency for Social Entrepreneurship

Friends, Family and Fools

Good Cooperation Savings and Loans Association

Expert Group on Social Economy and Social Enterprises

Good Deed Foundation

Gross Domestic Product

Global Impact Investing Network

Green Public Procurement

Information Technology

Most Economically Advantageous Tender 
NEETs

NESsT

NFCS

NPLs

NPO

OECD

P2P

PISA

RBF

RCT

RDCs

RGO

SaaS

SAW-B

SBI

SDGs

SME

SPF

SPO

TEPSIE

WISE

WWF

vc
Not in Education, Employment, or Training

Nonprofit Enterprise and Self-sustainability Team

National Foundation for Civil Society

Non-Performing Loans

Non-Profit Organisation

Organisation for Economic Co-operation and Development

Peer-to-Peer (Lending)

Programme for International Student Assessment

Responsible Business Forum

Randomised Control Trial

Regional Development Centres

Réseau Grand Ouest

Network of the French region Grand Ouest

Software as a Service

Solidarité des Alternatives Wallonnes et Bruxelloises

Social Business Initiative

Sustainable Development Goals

Small and Medium Enterprise

Specialisterne Foundation

Social Purpose Organisation

Theoretical, Empirical and Policy Foundations for Social Innovation in Europe

Work Integration Social Enterprise

World Wildlife Fund

Venture Capital 


\section{Executive summary}

Estonia has enjoyed significant economic growth in recent years, driven primarily by strong domestic demand and private consumption. However, the country still lags behind other OECD Member States as it suffers from persistent poverty and high inequality, as well as a shrinking working-age population.

Social innovation, social entrepreneurship and social enterprises are increasingly being put under the spotlight by Estonian policy makers and civil society as a promising and viable vehicle to tackle these challenges (see definitions in Box 1, Section 2). By coupling social objectives with economic value creation, the organisations operating in the fields of social innovation and social entrepreneurship can contribute to boosting local development, for instance by creating new enterprises and jobs or by (re)integrating disadvantaged individuals into the labour market. For instance, one estimate finds that social economy organisations, which include social enterprises, are estimated to account for $6.3 \%$ of jobs in the EU28. More generally, these organisations offer a pool of innovative solutions designed to improve the wellbeing and welfare of people and places.

Several conditions in Estonia provide fertile grounds for the rise and development of social entrepreneurship and social enterprises. Some positive factors include the dynamic civil society and rich welfare traditions, the accession to the European Union in 2004, and the recent reform of the municipal governance transferring greater competences and resources to local authorities. In addition, the vibrant start-up culture and the multiplicity of "bottom-up" initiatives has laid the ground for the ecosystem for social innovation to develop and flourish. However, a number of challenges, including the lack of coherent policy framework to support social entrepreneurship and social enterprises, are still preventing the field from further developing.

Policy-makers can therefore play a critical role in helping social entrepreneurs overcome these barriers by shaping enabling policy ecosystems that foster greater synergies and coherence between policy areas while reducing policy silos. Estonia has an opportunity to unlock the potential of social entrepreneurship and social enterprises, including by building on Estonia's achievements to support social innovation development.

\section{- Building a culture of social innovation and social entrepreneurship}

Social innovation and social entrepreneurship - which includes social enterprises - can contribute simultaneously to economic growth and to social and environmental sustainability. To achieve these objectives, putting in place enabling policy and institutional conditions is critical. Most importantly, all relevant stakeholders must share a common understanding and vision of what social innovation and social entrepreneurship are and how they can be scaled up, which is currently lacking in Estonia. To overcome this challenge, the Government could relaunch the Social Innovation Taskforce, which would be in charge of designing a national strategy to boost social innovation, social entrepreneurship and social enterprises. This would notably entail the adoption of official definitions, the development of new sources of finance, or the promotion of challenge prizes to stimulate innovation in particular in priority areas. 
- Supporting social entrepreneurship and social enterprises through institutional and legal frameworks

When well designed, legal frameworks explicitly support the development and build a common understanding of what social entrepreneurship and social enterprises are and how they can contribute to socio-economic development. Institutional frameworks play an equally important role. In Estonia, the current strategies lack an explicit focus to promote social entrepreneurship and social enterprises. Furthermore, public departments and agencies seem to have different understandings of what social enterprises are, do and the impact they have. To address that issue and build a common understanding, the Government could adopt official definitions of social innovation, social entrepreneurship and social enterprises in the upcoming governmental strategies. This would ideally go hand-in-hand with clearly identified coordinating structures and clarity regarding their roles and mission. The Prime Minister's Office and the unit in charge of SDG coordination could take the lead in designing and implementing national strategies conducive to the development of social entrepreneurship and social enterprises.

\section{- Improving access to finance to boost social entrepreneurship and social enterprises}

Although a number of opportunities exist to finance start-ups and SMEs and an alternative financing market is slowly emerging in Estonia, social enterprises face numerous financing challenges such as obtaining bank loans and guarantees and accessing mainstream financial schemes. For example, social enterprises, in particular in the form of non-profit associations (as many as 93\%), and foundations do not have access to public business support programmes and financial schemes. Overcoming these challenges could require removing legal barriers to ensure social enterprises have access to the same financial support mechanisms as private limited companies. Conducting an assessment to better understand the needs and provision of finance for social enterprises, and supporting the development of an intermediary to act as a social investment market, can be additional measures to facilitate social enterprises' access to finance.

\section{- Improving access to markets to promote social entrepreneurship and social enterprises}

Access to markets - public or private - represents an important source of revenue for social enterprises, notably in countries like Estonia where social finance is limited. Despite public procurement representing a significant market accounting for $13 \%$ of the GDP and $35 \%$ of the state budget, key roadblocks prevent social enterprises from reaping its full benefits. Some roadblocks include the prevailing use of the lowestprice criterion in bidding offers, and public sector commissioners and social enterprises lacking skills for procuring and bidding for contracts with social value. To address this skills gap, the Government could relaunch the Social Innovation Taskforce and, for instance, create a pool of trainers to deliver trainings on social considerations in public procurement. In parallel, mainstream businesses could be encouraged to integrate social enterprises in their supply chains by purchasing their services and/or goods to unlock the full potential of the collaboration between the private sector and social enterprises.

\section{- Building capacity and developing social entrepreneurial skills}

Developing social entrepreneurial capacity and skills can yield powerful policy gains. Not only can it nurture learners' personal development, but it also strengthens employability and equips citizens to engage actively with societal challenges. Although Estonia possesses high quality capacity building and business development programmes, social enterprises that are non-profit associations are unable to access these programmes due to their legal form. Additional barriers include a lack of effective provision of support services, in particular for social entrepreneurs and in the area of social impact measurement. To ensure social entrepreneurs are well equipped to realise their full potential, it is critical to better understand their unique skills challenges via relevant research (i.e., by leveraging a tool such as OSKA, which helps to identify skills needs and provides guidance to public stakeholders). It is also important to diversify the type of capacity building and skills development programmes (i.e., accelerators, workshops, short courses) while better linking them to the provision of finance and funding opportunities. 
- Action plan

Stemming from these key policy issues, the action plan presented below provides a detailed overview of all the policy recommendations included in this report. It identifies short, medium and long-term objectives. It also identifies key stakeholders in charge of implementing these recommendations. The rationale and the details of each policy recommendation summarised in the action plan are presented in the report. 


\section{Action plan}

\begin{tabular}{|c|c|c|}
\hline Recommendations & When & Who \\
\hline \multicolumn{3}{|l|}{ Building a culture of social innovation and social entrepreneurship } \\
\hline $\begin{array}{l}\text { Relaunch the Social Innovation Taskforce. } \\
\text { The Social Innovation Taskforce could develop a national strategy, endorsed officially by the Government } \\
\text { Office Strategy Unit and relevant ministries, to stimulate and scale up social innovation, social } \\
\text { entrepreneurship and social enterprises. The Strategy could then be integrated in the national, regional } \\
\text { and local development plans. More specifically, the Taskforce could adopt official definitions and develop } \\
\text { a narrative around the need for, and benefits of, social innovation, social entrepreneurship and social } \\
\text { enterprises. }\end{array}$ & & $\begin{array}{l}\text { Government Office Strategy Unit; } \\
\text { Ministry of Education and } \\
\text { Research; } \\
\text { Ministry of Economic Affairs and } \\
\text { Communications; } \\
\text { Ministry of Social Affairs; }\end{array}$ \\
\hline $\begin{array}{l}\text { Consider the use of challenge prizes to stimulate social innovation and social entrepreneurship in } \\
\text { priority areas. } \\
\text { Challenge prizes could be used alongside other traditional methods (research grants, commissioning } \\
\text { services, innovation labs, etc.) to develop new approaches as well as innovation capabilities. Any } \\
\text { challenge prize could focus on specific policy priority areas (e.g. youth unemployment, education and } \\
\text { skills, long-term care for the elderly, carbon reduction or health and wellbeing), and aim to enhance the }\end{array}$ & $\begin{array}{l}\text { Short- } \\
\text { term }\end{array}$ & $\begin{array}{l}\text { Ministry of Finance; } \\
\text { Ministry of the Interior; } \\
\text { Key stakeholders from public and } \\
\text { private sectors. }\end{array}$ \\
\hline
\end{tabular}


capabilities of citizens' associations, non-profit organisations and social enterprises to deliver public interest services.

\section{Supporting social entrepreneurship and social enterprises through institutional and legal frameworks}

Establish a national strategy to support the development of social entrepreneurship and social enterprises based on an assessment.

National and regional authorities could organise assessment workshops, using for example the OECD/EC "Better Entrepreneurship Policy Tool". This could provide a good basis to identify policy priorities and further explore the recommendations included in this report and notably the need to adopt official definitions and to improve coordination across levels of governments to boost social entrepreneurship and social enterprise development.

Adopt governmental strategies with an official definition of social entrepreneurship and social enterprises.

Adopting an official definition of both social entrepreneurship and social enterprises could be done in a participatory manner as part of the on-going process to prepare the new national strategy Estonia 20202035 and to revise other national strategic plans. In addition, clarifying existing legal provisions to explicitly allow associations to develop economic activities if they meet the criteria set in the official definition, would unlock their potential for growth.

Identify coordinating structures and clarify their role in promoting social entrepreneurship and social enterprises.

The Prime Minister's Office and the unit in charge of SDG coordination could coordinate public action to boost the development of social entrepreneurship and social enterprises and more broadly promote the national ecosystem, while ensuring coherence between national and subnational policies. The Social Innovation Taskforce and/or the Regional Development Centres could act as one-stop-shops offering advisory services and financial resources explicitly targeting social enterprises, irrespective of their legal form.

Short-to medium

term
Ministry of Economic Affairs and Communications:

Ministry of Social Affairs;

Ministry of Finance. 
Take advantage of the funding opportunities of the next Operational Programme for EU Cohesion Policy 2021-2027 to support social entrepreneurship development.

Estonia could draw from the EU funding including the ESIF, sustainable urban development under the ERDF, and community-led local development under EAFRD to develop and implement a coherent national agenda for social entrepreneurship development.

Improving access to finance to boost social entrepreneurship and social enterprises

\section{Carry out an assessment of the financing needs of social enterprises.}

An assessment could be conducted to identify the specific financing needs of social enterprises for all legal forms and to examine the provision of finance for such organisations. Such an assessment should include non-profit associations that generate revenue by selling goods and services, and organisations which, whilst not social enterprises per se, share many of their characteristics (e.g. SMEs and start-ups which have a strong social or environmental objective and socially responsible businesses). This assessment could consider the provision of finance to social enterprises as well as the capital requirements of social enterprises at seed, start-up, growth and consolidation stages.

Remove legal barriers to ensure an equal access to financing opportunities and support for social enterprises and mainstream businesses.

Remove legal barriers to ensure that social enterprises that are non-profit associations are able to access the same financial support mechanisms as private limited companies. Instead of focusing on the legal form, public organisations should consider whether an organisation has a solid business plan, the capacity to generate income and a sustainable business model.

Set up an intermediary to act as a social investment market builder and make access to finance easier for social enterprises.

Estonia could consider establishing or supporting an intermediary to develop a pipeline of social enterprises by focusing on the early stages of development. In the longer term, its role would be to help build a social investment market in order to support social enterprise development, regardless of their 
legal form. The new intermediary could provide financial support as well as networking opportunities and capacity building programmes (such as incubator and accelerator programmes).

Improving access to markets to promote social entrepreneurship and social enterprises

\section{Develop a training action plan on procuring social value.}

A training action plan can be developed based on the results of the Social Innovation Taskforce's assessment across the relevant ministries to identify the training needs of officials for procuring social value, and the training needs of social entrepreneurs to bid for public contracts. Training curricula could be tailored to the officials' roles in public procurement and needed level of expertise, and to the stage of development of social enterprises. The training action plan could be complemented with a monitoring mechanism for implementation.

\section{Create a knowledge-sharing group among the ministries dealing with sustainable procurement.}

A group of officials from different ministries who deal with sustainable procurement could complement formal training programmes and stimulate knowledge-sharing and peer-to-peer learning when it comes to concrete implementation of social and/or environmental considerations. This cross-ministry group should be comprised of technical level officials from all relevant ministries.

\section{Stimulate the cooperation between mainstream businesses and social enterprises.}

Awareness raising campaigns in media (e.g. social media, TV, radio) should highlight the social and/or environmental impact resulting from such a cooperation along with the benefits that both mainstream businesses and social enterprises could receive. Relevant networks, such as the Estonian Social Enterprise Network, could help to amplify the efforts of this endeavour.

Building capacity and developing social entrepreneurial skills

Embed an explicit social entrepreneurship component in entrepreneurship education programmes.

Mediumterm
Ministry of Finance;

Ministry of Economic Affairs and Communications;

Ministry of the Environment; Ministry of Social Affairs;

Ministry of the Interior. 
Social entrepreneurship could be mainstreamed into entrepreneurship education, and could include elements such as measuring social and environmental impact, building social enterprise business models, understanding social environmental issues and challenges, and co-designing solutions to social challenges with beneficiaries. The scope of existing university incubators or programmes (e.g. STARTER, Change-makers Academy) could be broadened to include projects prioritising social and environmental objectives.

\section{Conduct mapping of the skills needs of social entrepreneurs.}

Research should be conducted to gather data on the specific demand for, and supply of, skills for social enterprises. Such research should consider the needs of social enterprises, which are in the form of nonprofit associations and private limited companies. Existing tools, such as OSKA, could be leveraged to identify the skills needs of social entrepreneurs and social enterprises.

\section{Extend and diversify the capacity building offer for social entrepreneurs.}

The Government and the main providers of capacity building and business development support programmes could consider implementing alternative approaches to capacity building, especially those that are cohort based and fixed-term, for example by further connecting social entrepreneurs to potential investors or buyers. These providers could also set up accelerators and workshops or short courses on topics relating specifically to social enterprises such as setting up a social enterprise; scaling, dissemination and replication; transforming a non-profit into a social enterprise; and measuring social impact.

Ensure an equal access of social enterprises to mainstream business development programmes.

Social enterprises could be provided with a level playing field to access capacity building or business development support as mainstream businesses. For instance, the List of Public Benefit Organisations could be opened to social enterprises in the form of a private limited company. In addition, social enterprises could be made eligible to apply to the National Foundation for Civil Society (NFCS) for capacity building support.

Ministry of Economic Affairs and Communications;

Short-

term

Ministry of Education and

Research;

Ministry of Social Affairs. 


\section{The socio-economic and political context}

Estonia has benefited from significant economic growth over the past few years, primarily thanks to strong domestic demand and private consumption. The 2016 Work Ability reform contributed to boosting the national labour market performance through activation and rehabilitation measures for people with limited work ability. Yet, Estonia still lags behind other OECD countries in terms of poverty and income inequality, while being highly affected by a shrinking working-age population. To address these challenges, Estonia can tap into the opportunities arising from the recent reform of the municipal governance (2017) as well as its longstanding civic culture tradition, which emerged during the short-lived independence that took place in the $19^{\text {th }}$ century. This also laid the ground for the development of social entrepreneurship. However, the field only consolidated in its current form in the early 2000 s as different civil society actors attempted to find ways to make non-profit organisations more sustainable. Social entrepreneurship now features in the agenda of various ministries, but efforts are still needed in order to unlock the full potential of organisations operating in this field. This section provides a brief overview of Estonia's socio-economic and political context, and highlights recent developments towards increased recognition of social entrepreneurship and social enterprises.

\section{Socio-economic context}

\section{A growing economy}

Estonia has enjoyed significant economic growth in recent years, driven primarily by strong domestic demand and private consumption, which can notably be explained by high employment rates and fastgrowing wages. In 2018, the country's growth rate was at $4.8 \%$, but is expected to drop below $3 \%$ by 2020 as the economy hits capacity constraints (European Commission, 2019[3]; OECD, 2019[4]]).

Significant external demand and favourable commodity prices have also played an important role in sustaining the country's economic growth. Indeed, in terms of export performance Estonia has been outperforming its OECD counterparts for almost a decade (OECD, 2017[5]). To date, exports amount to over $75 \%$ of the country's GDP. In fact, Estonia has maintained a surplus in its account balance over the last six years due to large net exports of services (European Commission, 2019[3]).

Investment has been another driving force for Estonia's positive economic growth, especially in the aftermath of the 2008 financial crisis (OECD, 2017 $[5])$. Residential investment notably recovered after a housing downturn and is now strongly contributing to the country's economic growth (OECD, 2019[4]). However, investment's contribution to GDP is expected to drop in the next few years. More precisely, investment intensity is projected to stabilise around 24\% of GDP over 2019-2020 (European Commission, $\left.2019_{[3]}\right)$. 


\section{A well-performing labour market}

Estonia benefits from a well-performing labour market. While its economy was hit hardly by the 2008 financial crisis, by 2015 employment rate had picked up again, amounting to more than $70 \%$ of the workingage population, the rate that is well above the EU average and above the pre-crisis level (OECD / EU, $2018[6]$ ). This trend continued upward until 2017 , with an employment rate amounting to $77.1 \%$ of the total population aged 20-64 (European Commission, 2019 ${ }_{[3]}$ ). Part of this increase can be attributed to the Work Ability reform (2016), which determines the distribution of disability benefits and promotes activation and rehabilitation measures to help people with partial work ability transition from disability insurance to the labour force (European Commission, 2019 $9_{[3]}$ ). At the same time, the unemployment rate has decreased by approximately 10 percentage points since 2010 , the year where it recorded an all-time high of almost $19 \%$ (OECD, 2017 $[5]$ ). By 2017, the unemployment rate had dropped to $5.8 \%$ of the labour force, compared to the EU average rate of $7.6 \%$, and it is projected to decrease to $5.4 \%$ by 2020 (European Commission, $2019_{[3]}$; OECD, 2019 $\left.[4]\right)$. Despite a strong overall performance of the labour market, with an activity rate up to $83.5 \%$ in 2017 , some subgroups continue to experience low employment rates. For instance, the employment rate of women in couples with young children is low compared to other European countries (OECD / EU, 2018[6]). This is also reflected in Estonia's spending on active labour market policies per unemployed person as a percentage of GDP per capita, which was among the lowest across OECD countries in 2015 (OECD, 2017[5]).

\section{Decreasing but persistent inequality}

Despite Estonia's efforts to combat inequalities, the country displays mixed results on poverty and inequality reduction. On the one hand, the share of people living in low work intensity households has gone down since 2012 (European Commission, 2019 $\left.{ }_{[3]}\right)$. The incomes of the poor have also increased, notably thanks to a series of measures taken to raise the minimum wage (from EUR 278 in 2011 to EUR 470 in 2017) (OECD, 2017 $\left.{ }_{[5]}\right)$. On the other hand, income inequality remains among the highest in the OECD and above the EU average (OECD, 2017[5]; European Commission, 2019 $\left.9_{[3]}\right)$. As such, the household income of the richest $20 \%$ was 5.4 times higher than that of the poorest $20 \%$ in 2017 , thus still exceeding the EU average of 5.1. In addition, the proportion of the working-age population at risk of poverty has increased since 2011 and amounted to $20 \%$ in 2014, in comparison to the EU average of $17 \%$ (European Commission, 2019[3]; OECD / EU, 2018[6]).

Examining inequalities through the regional lens, the general trend is one of convergence of Estonia's income per capita towards the EU average since 2008. However, this convergence has not been homogenous across different regions within the country. The region of North Estonia outperforms Estonia's six other regions in seven of the OECD's well-being dimensions ${ }^{1}$ and it ranks in the top $20 \%$ of the OECD regions for jobs, access to services and access to education (OECD, 2018[7]). Within Northern Estonia, the capital region, Harju Region, has been more successful in catching up with the EU average than other regions. In fact, a large proportion of the wealth created is concentrated in the capital region. In 2016, Harju Region contributed to $64 \%$ of GDP and $52.7 \%$ of total exports (European Commission, $2019_{[3]}$ ). The challenges local governments face to ensure the provision of quality public services, such as the lack of resources and capacity, partially explain these territorial disparities and the unequal economic convergence (European Commission, 2019 $\left.{ }_{[3]}\right)$. Socio-economic factors also strongly contribute to these territorial inequalities. A striking example is East-Viru Region where labour market indicators and health indicators are recorded as the lowest across the country (European Commission, 2019[3]). The same conclusion applies to the Region's entrepreneurial sector: entrepreneurial activity remains the lowest in East-Viru Region with an average of 44 companies per 1000 inhabitants, less than half of the Estonian average of 91.5 companies in 2016. This indicates that while Estonia has managed to boost its overall

\footnotetext{
${ }^{1}$ These dimensions are jobs, access to services, civic engagement, education, health, environment and income.
} 
performance in entrepreneurship, regions have not equally benefited from economic convergence (European Commission, 2019[3]).

\section{Demographic trends}

Over the last decade, Estonia's working-age population has shrunk by $7 \%$, amounting to $65.8 \%$ of the total population in 2014 (OECD, 2014[8]). The ageing population and emigration are two key factors that can explain the drop. In 2017, the age dependency ratio was estimated to be $55.8 \%$ of the working population, putting a strain on the social security system $\left(\mathrm{UN}, 2017_{[9]}\right){ }^{2}$ While Estonia has been less vulnerable to brain drain than its Baltic counterparts have, and although immigration has outpaced emigration in recent years, more targeted policies might be needed to mitigate the contraction of Estonia's labour force.

\section{Political landscape}

Similar to other neighbouring countries, in Estonia the strong Soviet heritage has deeply affected entrepreneurial and civil society dynamism. Indeed, it is only in 1991 after 50 years of Soviet period from 1940 to 1991 that Estonia started developing its private sector. These efforts were also facilitated when Estonia joined the European Union in 2004, after negotiations that began in 1998. Since then, the Government has focused on industrial innovation as a driver to boost growth and employment, and address other key strategic challenges. Although social innovation and social entrepreneurship have not been considered per se as levers to address these challenges, opportunities could arise with the new municipal governance structure.

Since 2017, Estonia has been undergoing a deep restructuring of its municipal governance by streamlining and consolidating its 213 local administrative units into 79 municipalities. After several years of political discussions, these reforms materialised despite political change in the Government (Freedom House, 2018[10]).

The reform also intended to review the balance of power between the central administration and municipalities. The rationale behind having larger administrative units was to devolve more competencies to local authorities and provide them with more financial resources. In this endeavour, the Government agreed to modify the income tax law so that local governments could retain a greater proportion of their local tax revenues (Freedom House, 2018[10]).

This reform should help address one of the main issues constraining local governments, namely the scarcity of tax revenues. In 2016, tax revenues accounted for less than 15\% of local revenue in Estonia, placing it at the lowest ranking across OECD countries (OECD, 2018 $[11])$. The majority of local revenue is in fact composed of grants and subsidies. Spending in Estonia seems to be more decentralised than revenues: while subnational tax revenue amounted to less than $1.5 \%$ of total public tax revenue in 2016 , subnational government expenditure amounted to nearly $25 \%$ of total public expenditure (OECD, 2018 $[11]$ ). These trends suggest that while local governments do have expenditures, they are limited in terms of spending as they primarily rely on grants and subsidies rather than taxes.

\section{The roots of social entrepreneurship in Estonia}

The historical roots of social enterprises can be traced back to the 19th century, with the emergence of bottom-up initiatives (Kulbok-Lattik, 2015 $\left.{ }_{[12]}\right)$. In 1886, under the Russian Empire, visually impaired people

\footnotetext{
${ }^{2}$ The age dependency ratio is the sum of the young population (under age 15) and elderly population (age 65 and over) relative to the working-age population (ages 15 to 64 ).
} 
began selling brushes, an initiative that has been recognised as the precursor of modern day social enterprises (European Commission, 2019 [13]).

During Estonia's short-lived independence (1918-1934), civil society flourished, opening up new opportunities for the development of a long-lasting civic culture and the strengthening of a sense of citizenship among the Estonian population. In the same period, the country witnessed the rise of an agricultural cooperatives movement, marking the beginning of rural economic development. In 1928, about two-thirds of Estonian farmers were members of cooperatives as well as adherents to the Estonian Cooperative League founded in 1919 (European Commission, 2019 ${ }_{[13]}$ ).

Similar to other former Soviet Republics, Estonia collectivised private properties and land between 1940 and 1991, while prohibiting all attempts at private entrepreneurship. As part of the process of "Sovietisation", the country implemented Soviet state practices while restructuring its society (KulbokLattik, 2015 $\left.{ }_{[12]}\right)$. These societal and institutional transformations have left their mark on Estonian society, explaining the long-lasting negative attitudes towards anything qualified as "social", which might explain some of the mixed perceptions regarding social entrepreneurship.

From the mid-1980s onwards, a process of economic liberalisation took place, resulting in the legalisation of small state enterprises and private business undertakings. The dismantlement of the Soviet Union accelerated the privatisation of medium and large-scale state enterprises (Põder, $2017_{[14]}$ ). Following the dissolution of the Soviet Union, new types of entrepreneurial activities emerged in rural areas where half of the Estonian rural population was employed in the agricultural sector (European Commission, 2019 ${ }_{[13]}$ ). These events contributed to the rapid growth of private enterprise, with $90 \%$ of enterprises transforming into private enterprises by 1995 (Põder, 2017 $[14])$. It is worth noting, however, that the State intervention was not stable throughout the privatisation process (Põder, 2017[14]). The initial stages of the transition were characterised by a lack of state oversight, limited support structures for enterprises and legislative gaps. The mid-1990s saw a shift in the state's attitude towards entrepreneurship: state intervention increased together with international projects promoting the creation of business support services, and efforts towards institutional harmonisation with EU regulations ensued (Põder, 2017[14]).

As the country opened up its economy, it also undertook a visible shift in its welfare policy approach, moving slowly away from the legacy of the "state-socialist welfare traditions" towards a social welfare policy mix that merges a strong belief in free-market economy principles with concepts borrowed from the Nordic welfare model (Trumm, 2006 $\left[{ }_{[15]}\right) .{ }^{3}$ In 1995, the Social Welfare Act was passed, laying the foundations of the country's social welfare system. With Estonia accessing the EU in 2004, the development of the social welfare system was also impacted by EU policy guidelines (e.g. European Social Model, open method of coordination, etc.) and further supported by the use of EU structural funds (European Commission, 2019 [13]; Trumm, 2006 $[15])$. Yet, community-based social welfare has been increasingly put forth as a more efficient and pragmatic alternative, gaining the attention of the Government.

With social welfare policy being one of the key drivers behind the development of social entrepreneurship, the fusion of social-democratic and liberal welfare policies in Estonia has shaped social entrepreneurship practices (Raudsaar, 2016 $[16]$ ). The social welfare policy traditions that have inspired Estonian social enterprises to establish themselves inform the way each entity identifies its main partner. For instance, social enterprises inspired by the social-democratic approach (e.g. the Nordic welfare model) are more likely to view local municipalities as their main clients, whereas social enterprises stemming from the liberal approach would tend to target disadvantaged individuals as their main clients (Raudsaar, 2016[16]).

In the early 1990s, social enterprises were mainly identified as non-profit organisations in the form of unions or associations (many of them led by disabled people), subsidiaries of international organisations (e.g.

\footnotetext{
${ }^{3}$ According to Avo Trumm, researcher at the University of Tartu, the Social Welfare Act of 1995 draws its inspiration from the welfare laws of Denmark, Sweden and Finland. The influence of the Nordic welfare model can also be identified in the Social Benefits for Disabled Persons Act of 2001.
} 
SOS Children's Village, YFU Estonia) and new welfare service providers. In 2003, social entrepreneurship gained traction with the launch of the Good Deed Foundation, the first venture philanthropy organisation in the Baltics. The Good Deed Foundation was the first to introduce the term "social entrepreneur", which was then popularised thanks to the communication campaign of the country's first social entrepreneurship competition in 2005 (European Commission, 2019 $\left.{ }_{[13]}\right)$. However, some civil society actors consider the term to be elitist and non-inclusive of grass-root initiatives, hindering its adoption (European Commission, 2019 $[13])$.

It is only in 2009 that the concept of social entrepreneurship started to be adopted by different stakeholders, such as the National Foundation for Civil Society ${ }^{4}$ (NFCS or KÜSK), which played an important role in raising its visibility (European Commission, 2019 ${ }_{[13]}$ ). In addition, the introduction of support programmes specifically designed for social enterprises greatly contributed to that awareness-raising endeavour. These include the NULA incubator created by the NFCS to fund innovative solutions with a social impact and other capacity building grants for high-potential NGOs. In line with these efforts, the Estonian Social Enterprise Network (ESEN) was established in 2012 as an umbrella organisation bringing together social enterprises and other social purpose organisations. ESEN operates as both an advocacy organisation, with the aim to put social entrepreneurship on the agenda of relevant ministries (e.g. Ministry of Education), and as an incubator providing business development support to its members (ESEN, 2019 [17]). In 2012, ESEN became a strategic partner of the Ministry of the Interior to help it fulfil the objectives of the National Strategy for Civil Society 2015-2020. ESEN was also appointed member of the Social Innovation Taskforce, launched by the Government Office in February 2016 for a period of two years.

Finally, Estonia benefits from a dynamic civil society: Freedom House gave it the overall score of 1.75 qualifying it as "vibrant". ${ }^{5}$ In 2020, civil society was composed of 22500 registered non-profit organisations. Traditionally, NPOs have not been market-oriented but this tendency has been slowly shifting over the past decade with further efforts to be less dependent on public funding. In 2017, one fifth of Estonian NPOs generated some revenue from selling services or products (Tallinn University, $2019_{[18]}$ ). Although mapping accurately the number of social enterprises is difficult, due for example to self-identification biases that can lead to under or over estimations, an ESEN study ${ }^{6}$ identified 125 social enterprises in Estonia.

\footnotetext{
4 The National Foundation of Civil Society is a state-financed civil society fund established in 2008 by the Estonian Government.

5 The Freedom House ranks countries on a scale from 1 to 7 for different categories of the overall democracy score, 1 being the most democratic while 7 being the least democratic.

${ }^{6}$ ESEN calculated the number of social enterprises in Estonia for 2009-2012 and 2012-2016 by adding the number of NPOs and foundations with a business model, and the number of private limited companies with a social purpose. This was done manually through the examination of each entity's laws of association and annual reports. To this was added the number of self-identified social enterprises.
} 


\section{Building a culture of social innovation and social} entrepreneurship

Social innovation and social entrepreneurship are different policy areas, even if sometimes they develop in parallel (see definitions in Box 1). They should therefore not be confused. Still they are connected: when existing, both ecosystems can strengthen each other and when just one ecosystem exists, it can stimulate the emergence of the other, by providing a common and conducive ground and opportunities for multiple stakeholders. The ecosystem for social innovation already put in place in the country - although nascent and still to be improved - could represent a driver for the development of social enterprises. Few dedicated networks or intermediaries exist, along with other initiatives and institutional frameworks, which could thus be further leveraged and articulated to stimulate social innovation (and social entrepreneurship). For example, it will be key to examine how social innovation can be included in the on-going revisions of the National Development Plan for Civil Society or in the design of the new long-term strategy "Estonia 2035". Similarly, the Government has an opportunity to embed the social innovation agenda as part of the process of identifying new priorities and measures for the new programming period of the European Structural and Investment Funds (ESIF) (2021-2027). This section highlights some areas of strengths that could be further supported and challenging areas that might require additional policy attention. Policy issues are then included to provide more in-depth analysis and recommendations are formulated for guidance on the way forward.

\section{Strengths}

\section{New opportunities for public sector innovation}

Two structures have recently been established to support social innovation: the Innovation Lab and Accelerate Estonia. The Innovation Lab ${ }^{7}$, set up in 2018, sits in the Government Office' Strategy Unit and is a result of the Social Innovation Taskforce, notably funded through the European Social Fund (ESF). The Lab provides networking and training opportunities for civil servants and runs a number of co-designed experiments with different stakeholders, namely service users, citizens, public sector staff and civil servants. The Lab aims to train 600 policymakers in design methods and develop incremental innovations. Accelerate Estonia ${ }^{8}$, set up in 2019, is an innovation unit created by the Ministry of Economic Affairs, based inside Startup Estonia, which aims to generate disruptive innovations to tackle "wicked" policy problems. During its pilot phase, Accelerate Estonia aims to fund the development of business plans and prototypes

\footnotetext{
${ }^{7}$ For more information, see: https://digigovlab.ee/

${ }^{8}$ For more information, see: https://www.startupestonia.ee/focus-areas/accelerate-estonia
} 
in eight priority public policy areas, including social welfare, the labour market, the circular economy, health, construction, energy transition, the real-time economy and life environment. Even though both initiatives are relatively new, they are promising and highly complementary.

Estonia is widely recognised as a leading innovator in terms of digital governance. Under its flagship eEstonia programme ${ }^{9}$ a number of initiatives have been launched, including: e-Governance, e-Tax, eVoting, e-Health and most recently, e-Residency. The possibility for citizens to interact with the Government via its online portal opens up further opportunities for social innovation.

\section{Vibrant start-up ecosystem}

Estonia is also home to a thriving and dynamic start-up community. Despite its small size, Estonia relies on four "unicorns", which are start-up companies valued at over 1 billion USD (i.e. Transferwise, Bolt formerly Taxify, Skype and Playtech). The community is particularly strong in the fields of Software as a Service (SaaS) and FinTech, but is increasingly covering a diversity of sectors (Startup Estonia, 2019 ${ }_{[19]}$ ). In addition, there is a strong and growing start-up ecosystem that consists of:

- attracting international talent via its Startup Visa ${ }^{10}$ scheme;

- institutional support from Startup Estonia (which has supported more than 550 start-ups at the time of writing) (Startup Estonia, 2019[19]);

- a number of start-up incubators and accelerators such as StartUp Wise Guys ${ }^{11}$ and Technopol ${ }^{12}$;

- co-working spaces and a creative cluster centred in the Telliskivi Creative City ${ }^{13}$;

- a friendly business environment; and

- a growing venture capital market.

According to Startup Estonia's start-up database, a significant minority of these start-ups operate in the fields of health, education, green energy and the environment (Startup Estonia, $2019_{[19]}$ ). It is not currently possible to establish how large the 'social start-up' sector is since there is no data collected on the number of start-ups which have a primary social or environmental objective, although interviews conducted during the OECD study visit suggest it could be as much as $20 \%$ of the overall number of start-ups.

\section{Clear measures to promote "active citizenship"}

There are notable examples of promoting "active" citizenship. The Let's Do It Foundation's inaugural cleanup day brought together 50000 citizens to clean up the country in just five hours in 2008 (Let's Do It Foundation, 2019[20]). Active citizenship is also encouraged and promoted by the Government, most notably through the Active Citizens Fund. This fund, financed through the European Economic Area and Norway Grants, supports community-based and grassroots activities in the fields of democracy, civic activity, human rights and equal opportunities. Between 2014 and 2021, EUR 4 millions will be awarded through this fund. Its broader objectives are to empower disadvantaged groups and improve civil society's sustainability.

\footnotetext{
${ }^{9}$ For more information, please see: https://e-estonia.com/

${ }^{10}$ For more information, please see: https://www.startupestonia.ee/visa

${ }^{11}$ For more information, please see: $\underline{\text { https://startupwiseguys.com/ }}$

12 For more information, please see: https://www.tehnopol.ee/en/

${ }^{13}$ For more information, please see: https://www.visitestonia.com/en/telliskivi-creative-city
} 


\section{Support for entrepreneurship education at all levels of education}

The systematic entrepreneurship education programme introduced in 2016 aims to develop young people' competencies for entrepreneurship from an early age in order to enhance employability and social inclusion (see Section 6). The programme includes an entrepreneurship competence model, learning modules and resources for students (including some on social entrepreneurship), and modules for teachers' professional development. Courses in entrepreneurship are now compulsory for all students at university level. There is also a growing social entrepreneurship offer at university level, with universities offering optional modules on social entrepreneurship as well as the new Masters' Degree on Social Entrepreneurship at Tallinn University.

\section{Growing culture of Corporate Social Responsibility}

There is also a growing culture of Corporate Social Responsibility (CSR), which could stimulate social innovation, as companies try to raise their ethical standards. The Responsible Business Forum (RBF) is leading efforts on this front, with now 70 members including corporations from a range of sectors and publicly owned companies. The RBF organises an annual self-reporting questionnaire based on the Global Reporting Initiative framework and ISO 26000. More than 200 companies take part every year and approximately 70 of them are awarded the CSR label. This culture of CSR has, to some extent, created fertile ground for social innovation. For example, SEB Bank has set up an Innovation Centre as part of its CSR activity through which it supports social entrepreneurs and civil society organisations by giving them access to mentoring and training to help them set up, scale and develop sustainable business models. ${ }^{14}$

\section{Challenges}

\section{Lack of a common understanding of the concept of "social innovation"}

Up until now, Estonia has not agreed on a common official definition of social innovation. The relevant ministries, departments and public bodies (see Annex 1.A) do not share a common understanding and narrative about the role and benefits of social innovation. Some public bodies have emphasised the role of social innovation in the provision of social and employment services and the potential of citizens' association to provide public services (Ministry of the Interior, 2014[21]) while others have promoted social innovation by developing innovation capability in the public sector (Government, 2017[22]). However, to better promote social innovation it is important to develop a common understanding of the notion, by distinguishing it notably from social entrepreneurship and social enterprises. To rely on a commonly agreed and official definition is indeed critical in order to develop a social innovation strategy.

\section{Few dedicated policies, funds, institutions and networks to support social innovation}

In Estonia, there is no shared understanding of the potential beneficial impact of social innovation on the country's social and economic development across the Government and the public sector. This might explain why there are so few dedicated funds, institutions, networks or policies that specifically target social innovation. An exception is the Social Innovation Taskforce that was set up in 2016 for a period of two years to develop recommendations for increasing innovation capabilities within the public sector and across society more broadly, as well as to develop more effective public services through social innovation. The Taskforce notably included representatives of different ministries (Finance, Interior, Social Affairs, Economic Affairs and Communication) and the Government office, as well as relevant associations, networks and research institutes working on social innovation and social enterprises. One of the key outcomes of the Taskforce was the establishment of the public-sector Innovation Lab, which seems to be

${ }^{14}$ For more information, please see: https://www.seb.lt/eng/innovation-centre 
a promising initiative (see above). In terms of social innovation, however, the Taskforce had a very narrow scope and looked solely at social enterprises. It considered a number of issues: whether or not to create a certification system for social enterprises; whether or not to establish a new financial instrument for social enterprises; and how procurement processes could be adapted to support social enterprises through a pilot project. While there are clear and important links between social enterprises and social innovation, the Taskforce's impact may have been limited by this narrow focus. It may be preferable to look more broadly at the development, testing and scaling of innovative solutions to social challenges, irrespective of the sector from which these innovations emanate. Furthermore, for many of the recommendations formulated by the Taskforce, no clear follow-up by the Government and/or relevant ministries seems to have occurred. Beyond the public sector, across academia and civil society, there is a similar lack of dedicated social innovation networks and institutions.

\section{Policy Issues}

\section{Establishing a common understanding of social innovation}

Social innovation can promote multiple goals: ensuring economic growth and competitiveness along with social and environmental sustainability, which can in particular be captured by innovative social enterprises. However, for social innovation to achieve these objectives, it requires enabling conditions, institutional support and appropriate public policies. Most importantly, all relevant stakeholders must share a common understanding, as well as a vision for how it can be generated and scaled up. It is also important to recognise that social innovation is contingent on socio-economic and cultural factors varying depending on the country. It is therefore necessary for the Government to work on a grounded definition of social innovation in the Estonian experience for it to resonate and be accepted by local stakeholders. The table below provides definitions, which are commonly agreed at the international level and that could be used in the framework of a participatory and inclusive process.

Policymakers could consider taking an ecosystem approach to social innovation development. Broadly, this means ensuring that there is an appropriate supply of and demand for social innovation, as well as intermediaries that can effectively link the two. On the supply side, this may include funding for early stage ideas, growth and scaling up; and developing the skills and capacities of current and potential social innovators (including citizens, service users, and other stakeholders) through business development and other support services. On the demand side this may include, for example procurement and commissioning, developing evidence of impact by mainstreaming impact measurement, and/or stimulating private demand through personal budgets or tax incentives. As aforementioned, there are few dedicated social innovation intermediaries in Estonia. However, intermediaries can play a critical role in ecosystem building, most notably those that effectively combine the provision of financial support and non-financial support with networking opportunities for social innovation actors between and across fields and sectors. Currently, the Government plans do not set out a clear overarching framework for promoting and stimulating social innovation. It is important to highlight the potential benefits of social innovation by embedding, mainstreaming and integrating support for social innovation in the country's institutional landscape and Estonia's national long-term strategic plans. 


\section{Box 1. Defining social innovation, social entrepreneurship and social enterprises}

Social innovation is about designing and implementing new solutions that imply conceptual, process, product, or organisational change which ultimately will improve the welfare and wellbeing of individuals and communities (OECD LEED, $2000_{[23]}$ ). The aim is notably to meet social demands traditionally not addressed by the market or existing institutions and generally, but not exclusively, directed towards vulnerable groups in society. Social innovations aim to address societal challenges in which the boundary between "social" and "economic" blurs and which are directed towards society as a whole. For instance they often aim to reform society to encourage a more participative arena where empowerment and learning are sources and outcomes of well-being (BEPA, 2015[24]). Although social entrepreneurs often adopt socially innovative approaches, they do not have the monopoly of social innovation, which can also be developed in the public, non-profit or traditional business sectors.

Social entrepreneurship is often defined as the process through which specific types of actors - the "social entrepreneurs" - create and develop organisations that may be either social enterprises or other types of organisations (Defourny, 2008[25]; Mair and Martí, 2006 ${ }_{[26]}$. Beyond the idea of process, social entrepreneurship designates a field including a broad set of initiatives with a social impact dimension in a spectrum ranging from for-profit to non-profits (Nicholls and Huybrechts, 2012[27]; OECD, 2010[28]). Social enterprises are only a subset of this field in which commercial models are used as the vehicle to achieve social objectives (Nicholls, 2006[29]; Thompson, 2008[30]).

Building on the first conceptualisation adopted by the OECD (OECD, 1999 $\left.{ }_{[31]}\right)$ and concomitant work done by the EMES Research Network, the European Commission identified a social enterprise as:

- An operator in the social economy whose main objective is to have a social impact rather than make a profit for their owners or shareholders (social mission criterion);

- It operates by providing goods and services for the market in an entrepreneurial and innovative fashion (market orientation criterion);

- It uses its profits primarily to achieve social objectives (social mission criterion);

- It is managed in an open and responsible manner (governance criterion); and

It involves employees, consumers and stakeholders affected by its commercial activities (governance criterion) (European Commission, 2011[32])

\section{Incentivising social innovation through challenge prizes}

The use of challenge prizes in Estonia could be an effective way of crowdsourcing solutions to specific social and environmental challenges, uncovering new sources of social innovation and building the skills and capabilities of potential innovators.

In the last two decades, there has been an explosion in the use of challenge prizes across the world ${ }^{15}$ to stimulate innovation (Burstein and Murray, 2016[33]). This has been underpinned by new technologies that enable crowdsourcing and new trends in innovation policy and management with an emphasis on open innovation strategies. More recently, various governments have started to use prizes to incentivise

\footnotetext{
${ }^{15}$ It is important to make a distinction between challenge prizes, also known as innovation inducement prizes, where the outcome is unknown, and ex post reward or recognition prizes, such as the Nobel Prize, where something has already been achieved. A challenge prize involves identifying a problem, publicising the problem and potential reward, and then awarding the prize to the team with the best solution.
} 
innovation and solve social challenges. In the United States, prize competitions became an official element of the Government's innovation strategy. Since its launch in 2010, Challenge.gov has posted nearly 1000 challenge prizes from more than 100 public agencies. ${ }^{16}$

Research suggests that challenge prizes are effective because they serve to:

- attract a broader range of participants, with a more diverse set of skills and expertise;

- appeal to people's intrinsic motivations;

- leverage additional funds;

- influence public perception and focus communities on specific problems;

- create new collaborations between problem-solvers; and

- solve problems in a more cost-effective way than traditional approaches such as in-house innovation teams or research grants (Jeppesen and Lakhani, 2010[34]; Gök, 2013[35]; Kay, 2011 [36]; McKinsey \& Company, 2009[37]; Ballantyne, 2014[38]).

It has also been argued that "prizes are especially suitable when the goal can be defined in concrete terms but the means of achieving that goal are too speculative to be reasonable for a traditional research program or procurement" (Kalil, 2006 ${ }_{[39]}$ ). Evidence suggests that there are even positive effects for non-winning participants. One evaluation found that "publicity, attention, credibility, access to funds and testing facilities, community building" were benefits for non-winning participants (Murray et al., 2012[40]). Others have identified potentially harmful effects of challenge prizes, most notably the fact that risk is shifted onto participants and that the hours spent working on proposals and solutions by "losing" participants could be seen as a "waste" of time and effort (Starr, 2013[41]).

The way a challenge prize is organised can help to mitigate some of these risks. For example, some competitions have a stage-gate model to identify potential solutions at the earliest stage; some share rewards among multiple winners instead of a winner-takes-all model; some competitions include an incubation phase to provide support to finalists; and some create opportunities for peer collaboration at various stages during the process. One example is Ratkaisu 100, organised by Sitra in Finland between 2016-2017, which combined a social incubator with a challenge prize model (see Box 2). The competition, which focused on education and work, awarded EUR 1M two winning teams, Positive CV and Headai to implement their ideas.

\section{Box 2. Ratkaisu 100, Finland}

Ratkaisu was organised by Sitra, the Finnish innovation agency, between 2016 and 2017 to develop social innovations in the field of education and work. The two-year challenge consisted of three stages. First, the public was asked to identify what they thought was the main social challenge affecting the whole country. Second, Sitra launched a public call for teams with diverse and multi-disciplinary backgrounds who wanted to create socially innovative solutions in the fields of education and work. Third, the 15 teams selected after stage 2 received incubation support while developing their solutions. Two teams, Positive CV and Headai, were awarded the prize of EUR 1 million to implement their ideas. They were chosen by an independent jury that evaluated the effectiveness, innovativeness and feasibility of the ideas put forward.

Source: (Tuukka Toivonen, 2018[42])

Similarly, the European Commission's Social Innovation Competition, which has been running since 2013 to crowdsource solutions to societal challenges, also provides support to participants. The 30 semi-finalists

${ }^{16}$ For more information, please see: https://www.challenge.gov/ 
receive a package of support including a dedicated social innovation mentor, a 3-day residential training academy and opportunities to connect with their peers. In the final stage, 10 finalists are selected and given the opportunity to publicise their innovations at the final Awards Ceremony in Brussels. Three winning teams receive EUR 50 000. The current edition on Challenging Plastic Waste, seeks innovative approaches to reducing demand for plastic or recycling existing plastic waste. ${ }^{17}$

\section{Recommendations}

\section{Relaunch the Social Innovation Taskforce}

Estonia could boost social innovation by relaunching the Social Innovation Taskforce. The Taskforce would be responsible for developing a national strategy, articulated with national, regional and local development plans, to stimulate and scale up social innovation, social entrepreneurship and social enterprises. Based on the recommendations already formulated by the Taskforce in the past, as well as this report, the Taskforce could adopt official definitions of social innovation, social entrepreneurship and social enterprises endorsed by the Government and relevant ministries. The Taskforce could also develop a narrative about the need for and benefits of social innovation, social entrepreneurship and social enterprise in Estonia and could consider in particular how to:

- stimulate social innovation and social entrepreneurship in key challenge areas such as healthcare or unemployment (this could comprise incubator programmes, including innovative social enterprises, challenge prizes and/or funding for early stage ideas and projects, including those by social enterprises);

- scale-up social innovation (this could include, for example, new funding models and instruments, procurement and commissioning, examining regulatory frameworks, etc. which could also target social enterprises);

- adapt and replicate promising social innovation pilots, experiments and programmes;

- develop new sources of finance for social innovation, which could also target those social innovations carried out by social enterprises;

- empower users to innovate themselves (this could include funding for early stage ideas, challenge prizes, tools and toolkits, support services, new community networks, etc.); and

- articulate clearly measures dedicated to promote social innovation together with measures targeting more particularly social entrepreneurship and social enterprises.

\section{Consider the use of challenge prizes to stimulate social innovation and social entrepreneurship in priority areas}

Challenge prizes are an effective method for incentivising social innovation and social entrepreneurship. They can attract a wide pool of potential innovators to develop new solutions to societal challenges in a cost-effective manner. Challenge prizes could be used alongside other traditional methods (research grants, commissioning services, innovation labs, etc.) to develop new approaches as well as innovation capabilities. Any challenge prize could focus on specific priority areas, such as youth unemployment, education and skills, long-term care for the elderly, carbon reduction or health and wellbeing, and aim to enhance the capabilities of citizens' associations, non-profit organisations and social enterprises to deliver general interest services.

\footnotetext{
${ }^{17}$ For more information, please see: https://eusic.challenges.org/the-competition/
} 


\section{Supporting social entrepreneurship and social enterprises through institutional and legal frameworks}

Since its second independence in 1990, Estonia has introduced major reforms to its public governance system as well as institutional and legal frameworks to promote entrepreneurship, albeit without a specific focus on social entrepreneurship. The current revision of the long-term national strategic plans offers an opportunity to support explicitly the development of social entrepreneurship and to build a common understanding of what social enterprises are and how they can contribute to the socio-economic development of the country. However, existing public resources across Government levels could be better coordinated and promote explicitly social entrepreneurship and social innovation. This is notably the case of the fifteen regional development centres (RDCs) that have been set up at municipal level in 2003 to support entrepreneurship, through financial and business development support for example. This section thus presents some of the key strengths of existing institutional and legal frameworks supporting entrepreneurship and civil society development and outlines key challenges and policy issues that prevent the field from further expanding. Finally, the section provides policy recommendations to unlock the potential of existing public frameworks and resources to target and support explicitly social entrepreneurship.

\section{Strengths}

The administrative reform established a clear and complementary allocation of competences across levels of government, which open-up new opportunities for social innovation and social enterprise development. National governments and municipalities established partnerships to support RDCs at regional level, serving commercial enterprises and non-profit organisations, including social enterprises adopting one of these two legal forms. Finally, long-term strategic plans have started to cover key dimensions of social enterprises.

\section{An institutional framework supportive of entrepreneurship and civil society at national level}

At national level, an encompassing institutional framework exists to support enterprises and non-profit organisations, including social enterprises. The Ministry of Interior (which manages the civil society 
portfolio), the Ministry of Finance (which notably manages the ESIF), and the Ministry of Social Affairs all provide funding, resources and services to:

- commercial enterprises, including social enterprises in the form of a limited company, and

- non-profit organisations, including social enterprises in the form of an association or foundation.

Each ministry has nonetheless its own specific strategy, funding programme, rules and procedures.

In addition, in terms of public agencies providing financial support, Invest Estonia is dedicated to commercial companies and the National Foundation of Civil Society is dedicated to non-profit organisations, both of which include social enterprises. The table in Annex 1.A, presents an overview of the main public actors involved and schemes implemented to support social enterprises regardless of their legal form.

\section{Potential of national strategic frameworks to open up opportunities for social entrepreneurship}

The overarching national strategy "Estonia 2020" developed by the Estonian Government to achieve the "Europe 2020" objectives and the 50 different sectoral long-term plans offer a conducive framework for entrepreneurship and civil society development. Their on-going revision can open up new opportunities for social entrepreneurship development. Since 2019 and throughout 2020, the implementation and impact of these strategies is being evaluated with a view to revise and extend them for the next decade. The objective is also to provide a coherent basis for the next programming period of the ESIF and for the new principal long-term strategy Estonia 2035. The following table provides on overview on the three strategic plans that are most relevant for social entrepreneurship development.

Table 1. Strategic plans relevant to social entrepreneurship

\begin{tabular}{|c|c|c|c|}
\hline & $\begin{array}{l}\text { Entrepreneurship } \\
\text { Growth Strategy }\end{array}$ & Civil Society Development Plan & $\begin{array}{l}\text { Social development } \\
\text { and employment } \\
\text { policies and welfare } \\
\text { development plan }\end{array}$ \\
\hline $\begin{array}{l}\text { Implementing } \\
\text { agencies }\end{array}$ & $\begin{array}{l}\text { Ministry of } \\
\text { Economic Affairs } \\
\text { and } \\
\text { Communications }\end{array}$ & $\begin{array}{l}\text { Ministry of Interior; Ministry of } \\
\text { Finance; National Foundation of } \\
\text { Civil Society }\end{array}$ & $\begin{array}{l}\text { Ministry of Interior; } \\
\text { Ministry of Social } \\
\text { Affairs; Municipalities }\end{array}$ \\
\hline Objectives & $\begin{array}{l}\text { Promoting } \\
\text { competitiveness, } \\
\text { internationalisation, } \\
\text { smart specialisation } \\
\text { strategies and } \\
\text { entrepreneurship }\end{array}$ & $\begin{array}{l}\text { Addressing societal challenges and } \\
\text { providing quality } \\
\text { services in } \\
\text { healthcare, } \\
\begin{array}{l}\text { environmental } \\
\text { protection and } \\
\text { development }\end{array}\end{array}$ & $\begin{array}{l}\text { Effectively matching } \\
\text { labour needs }\end{array}$ \\
\hline Key measures & $\begin{array}{l}\text { Provision of market- } \\
\text { based financial } \\
\text { instruments for } \\
\text { companies and the } \\
\text { development of } \\
\text { entrepreneurial } \\
\text { skills, in particular } \\
\text { for tech-intensive } \\
\text { companies }\end{array}$ & $\begin{array}{l}\text { - Providing resources for } \\
\text { associations to develop, } \\
\text { through: financial assistance, } \\
\text { fiscal advantages, counselling } \\
\text { from RDCs, impact } \\
\text { measurement, increased } \\
\text { capacity to recruit volunteers } \\
\text { and ability to raise grants } \\
\text { - Providing opportunities for } \\
\text { income generation }\end{array}$ & $\begin{array}{l}\text { Providing assistance } \\
\text { to workers in the } \\
\text { labour market; } \\
\text { Bringing people with } \\
\text { reduced working } \\
\text { capacity to the labour } \\
\text { market }\end{array}$ \\
\hline
\end{tabular}




\begin{tabular}{l|l|l|lr}
\hline $\begin{array}{l}\text { Targets social } \\
\text { enterprises }\end{array}$ & $\begin{array}{l}\text { Not explicitly but } \\
\text { mentions } \\
\text { responsible } \\
\text { business practices }\end{array}$ & $\begin{array}{l}\text { Explicit mention of social innovation } \\
\text { and social entrepreneurship }\end{array}$ & $\begin{array}{l}\text { Focus on work } \\
\text { centres } \\
\text { organisations and } \\
\text { employing people } \\
\text { with special needs }\end{array}$ \\
\hline
\end{tabular}

Source: OECD elaboration based on Ministry websites. ${ }^{18}$

\section{A public governance model conducive to social innovation and social entrepreneurship}

The co-development of these strategies is part of governance structures and procedures applied by the Estonian Government to promote the development of social enterprises based on the following guidelines:

- In preparation of the Estonia 2035 strategy and the update of relevant sectoral strategies, the State Chancellery commissioned a comprehensive study to analyse the support system for social entrepreneurship. The Foresight Studies Unit of the State Chancellery has been in charge of the interim impact evaluation of the Civil Society Development Plan. This work is aimed at facilitating horizontal co-ordination and defining strategic priorities in cross-departmental action plans.

- Estonia is in early stage in implementing horizontal coordination structures in its public administration. One example is the role played by the Prime Minister's Office in coordinating the implementation of the Sustainable Development Goals (SDGs) across policy areas and levels of government, to ensure policy coherence.

- Set up on an experimental basis, an innovation lab is established in the prime Minister's Office for three years to further the work of the previous Social Innovation Taskforce. The Innovation Lab focuses on bringing together different public departments and stakeholders, raising awareness about innovation, and building innovation capacities inside the public sector through training of civil servants. The lab worked on social value criteria used in public procurement, the recognition of social enterprises through a label, and new financial instruments for social enterprises.

- To reinforce participatory policy-making, the Estonian Social Enterprise Network became a member of the Social Innovation Taskforce in 2016 to contribute to its sub-committees on social entrepreneurship development. The Ministry of Interior established "strategic partnerships" with civil society organisations and networks, and with the Estonian Social Enterprise Network, in charge of monitoring and assessing social enterprise actions under the Civil Society Development Plan.

\section{Strengthened municipalities and RDCs}

The territorial reforms adopted in Estonia give stronger competences to municipalities and RDCs to support socio-economic development, including through specific policies targeted at entrepreneurship and social entrepreneurship. The 2004 Act on the Promotion of Local Government Merger and the 2016 Administrative Reform introduced a two-level governance and merged a number of municipalities in order to strengthen the capacity of local authorities through a new allocation of competences across levels of government $\left(\mathrm{OECD} / \mathrm{UCLG}, 2019_{[43]}\right)$. The State competences relevant to start-ups and development of

\footnotetext{
18 Please see: https://kasvustrateegia.mkm.ee/index eng.html;

https://www.siseministeerium.ee/sites/default/files/elfinder/article files/kodar 2011-2014 eng 0.pdf

https://www.sm.ee/sites/default/files/content-editors/eesmargid ja tegevused/welfare development plan 20162023.pdf
} 
social enterprises were divided between the national Government, its agencies or social security insurance, and the municipalities (15 urban "towns" and 64 rural "parishes").

Through the mergers, the reform gave municipalities the opportunity to establish joint projects and agencies, for instance in the fields of economic development or social welfare. One of the key competences of municipalities is indeed the provision of social welfare (social services, social benefits, emergency social assistance and other assistance to the person) but municipalities can also cooperate in other fields (e.g. joint school services, public transport).

In addition, the administrative reform strengthened the role of the 15 RDCs, set up by municipalities in 2003 as independent foundations in each region, to support entrepreneurship at the local level. Initially, RDCs mainly collaborated with Enterprise Estonia. More recently, the National Foundation of Civil Society became their second important partner, along with the municipalities of the counties and the Ministries of Economic Affairs and Social Affairs. The State Support Center, an agency supervised by the Ministry of Finance, provides financial support to the RDC Network.

Today, RDCs offer free counselling and mentoring, and training services for start-ups and companies, nonprofit associations and foundations, and, more recently, also for local authorities, in partnership with all relevant national ministries and agencies.

\section{Challenges}

\section{Lack of explicit and focused policy to develop social enterprises}

The current national strategies previously mentioned do not explicitly, or only rarely, include specific programmes to promote social enterprises and social entrepreneurship. The lack of explicit policy to develop them thus undermines their potential to expand further.

Furthermore, the Operational Programme for EU Cohesion Policy 2014-2020, which was designed to cofinance a variety of national support measures for companies or associations active in the fields of employment, wellbeing, and community development, has not explicitly highlighted the role played by social enterprises. It has not allocated any ESIF contributions to the investment priority $n^{\circ} 9 \mathrm{v}$ "social entrepreneurship.

\section{Insufficient coordination across government levels and existing public initiatives}

Several policy initiatives and strategies exist in Estonia to promote entrepreneurship and civil society development (see previous tables and annexes). Yet, these are not always well articulated and do not always explicitly mention social enterprises. This can be noted in particular for social enterprises transitioning from grant-based (e.g. association) to market-based revenue (e.g. limited company) models, for which adequate support seems to be missing. Measures to support non-profit associations and companies are not well articulated nor coordinated, and thus do not provide associations with incentives to expand their economic activities, or for enterprises to strengthen their social mission and increase their social impact.

In addition, different public departments and agencies have a different coordination approach and understanding of what social enterprises are, what they do, or what impact they have.

\section{Limitations of existing legal forms for social enterprise development}

In Estonia, social enterprises can be established under different legal regimes. However, existing legal forms offer both benefits and pitfalls in terms of entrepreneurial development. The following examples illustrate the complexity faced by social enterprises depending on the legal form they adopt: 
- If they choose to adopt the non-profit association form, the legal provisions related to their social purpose and activities (non-profit associations Act, § 1 (1)) may cause conflicts for emerging social enterprises that manage to increase their revenues by selling their products or services because this might not be considered as a "social purpose".

- Similarly, the criteria for awarding the public benefit status (income tax break) to an association, which requires that "the association operates for charitable purposes", may block social enterprises from trading goods and services at market prices.

- In addition, the prohibition of "the transformation of a non-profit association into a legal person of a different class" (non-profit associations Act, $\S 1$ (4)) impedes associations to transform into limited company, which represents administrative and financial barriers hindering their development.

- Last but not the least, social entrepreneurs who adopt the legal form of commercial association "Tulundusühistu" report that it is difficult for them to distinguish their commercial activities from their general interest services, which then limits their possibility to access any public support and/or tax break.

\section{Policy issues}

\section{Adopting an official definition of social entrepreneurship and social enterprises}

Different public departments and agencies have different understandings of what social enterprises are and do, and the same goes for social entrepreneurship. The lack of a commonly agreed definition of social enterprises, regardless of their legal form, does not favour their development and visibility.

The adoption of an official definition of social enterprises and social entrepreneurship could notably provide a clear framework to remove existing barriers in the legal forms adopted by social enterprises. Indeed, existing legal forms adopted by social enterprises can either facilitate or limit the establishment and development of social enterprises:

- associations and foundations can employ volunteers, whereas commercial associations and limited companies do not have this opportunity;

- a public benefit status may be granted to associations and foundations working in the public interest, but not to commercial associations and limited companies; and

- hybrid organisations can be established by non-profit associations which own a limited company (as a trading or development arm), or vice versa.

The table in Annex 1.A provides an overview of the key features, opportunities and challenges of the different legal forms that social enterprises can adopt in Estonia.

Overall, social enterprises mostly adopt the legal form of an association, and therefore qualify for the public benefit status. This confers them income tax privileges and the right to receive donations from companies and individuals. However, the restrictive legal provisions on economic activities of associations makes it challenging for social enterprises to grow by increasing their share of market income.

Regarding social enterprises adopting the limited company legal form, there is no tax break or other incentives, e.g. employing volunteers.

Hybrid organisations are able to benefit from both streams of public support (for companies and for NGOs) regarding access to start-up and development support, funding through grants and loans, or public procurement. 
A new official definition of social enterprises could aim at removing these barriers for organisations that meet a common set of criteria aligned with the European Commission SBI initiative definition (see Box 1 in Section 2). This means that the Government would not necessarily need to create a new legal form but could rather extend the scope of the public benefit status to limited companies and commercial associations and allow associations to generate profits from trade. This would then increase the visibility and recognition of social enterprises and unlock their potential for growth.

The extension of the public benefit status would also generate a level playing field between social enterprises in the legal form of an association, and those established as limited companies. It would finally reduce the need for social enterprises to establish hybrid entities, which is causing additional administrative burden.

\section{Leveraging and coordinating existing public initiatives and resources to promote social entrepreneurship}

Based on a commonly agreed definition of social enterprises and social entrepreneurship, the Government could invite relevant stakeholders across government levels to take stock and coordinate existing public initiatives and resources to target social entrepreneurship explicitly. Indeed, the current national strategies do not, or only indirectly, include programmes to promote social enterprises and social entrepreneurship.

In particular, strategies at national level should be well articulated with municipal and regional frameworks and could feed into the next programming period of the ESIF, which is a major source of funding at EU level to promote social entrepreneurship.

The revisions of the public long-term national strategic plans and the Estonia 2035 strategy offer an opportunity to develop a legal definition of social enterprises and social entrepreneurship with relevant stakeholders. It is also an opportunity to overcome the non-profit/for profit company divide in allocating public support through integrated support structures and schemes.

Opportunities triggered by the territorial reform should also be leveraged to promote explicitly social entrepreneurship and social innovation. For instance, RDC networks or municipalities could support more explicitly social entrepreneurship and social innovation in a coordinated manner.

However, in order to avoid inconsistencies and help stakeholders navigate the field, the Government could provide a virtual and physical platform to map and articulate the different public initiatives and resources. This would also allow regional and municipal actors to exchange on what exists and remains to be done.

\section{Recommendations}

\section{Establish a national strategy to support the development of social entrepreneurship based on an assessment}

Clearly identifying and articulating existing public resources and stakeholders needs is critical to support the development of social entrepreneurship and social enterprises. In that endeavour, national and regional authorities could organise assessment workshops, using for example the OECD/EC Better Entrepreneurship Policy Tool. ${ }^{19}$ This could provide a good basis to identify policy priorities and further explore the recommendations included in this report, and notably the utility of adopting an official definition and to improve coordination mechanisms to boost social entrepreneurship development.

\footnotetext{
${ }^{19}$ For more information about the online tool, please see: https://www.betterentrepreneurship.eu/
} 


\section{Adopt governmental strategies with an official definition of social enterprises and social entrepreneurship}

Adopting an official definition of both social enterprise and social entrepreneurship could be done in a participatory manner as part of the on-going process to prepare the new national strategy Estonia 20202035 and to revise other national strategic plans. Developing an official definition of social enterprise is indeed helpful to capture the variety of their legal forms and allow organisations that have the potential and interest to transform into a social enterprise, to do so. This official definition could give an adequate framework to extend the public benefit status to include limited companies and commercial associations that meet the criteria set in the official definition. Along the same lines, clarifying existing legal provisions to allow explicitly associations to develop economic activities, if they meet the criteria set in the official definition, would unlock their potential for growth.

\section{Identify coordinating structures and clarify their role in promoting social entrepreneurship and social enterprises}

Coordination is needed to facilitate the implementation of national strategies conducive to the development of social entrepreneurship. It is important to clearly identify coordinating structures and clarify their roles and missions. For example, the Prime Minister's Office and the unit in charge of the SDG coordination could coordinate public action to boost the development of social enterprises and more broadly promote the national ecosystem. The RDCs could act as one-stop-shop advisory services and financial resources facilitators for social enterprises, irrespective of their legal form. Multilevel governance should also make sure that policies adopted at national, regional and municipal level are complementary and address all important policy areas for social entrepreneurship development.

\section{Take advantage of the funding opportunities of the next Operational Programme for EU Cohesion Policy 2021-2027 to support social entrepreneurship development}

Funding the above-mentioned actions under the ESIF, sustainable urban development under the ERDF, and community-led local development under EAFRD could be explored. With social innovation and social enterprise themes high on the agenda of the European Commission ${ }^{20}$, Estonia could draw from these funds in advantageous conditions to develop and implement a coherent national agenda for social innovation and social entrepreneurship development.

\footnotetext{
${ }^{20}$ Please see: http://ec.europa.eu/regional policy/en/2021 2027/ for the new priorities for the European Structural and Investment Funds (ESIF).
} 
36 


\section{Improving access to finance to boost social entrepreneurship and social enterprises}

The financing landscape for social enterprise development in Estonia is embryonic: there is a significant lack of information regarding the specific financing needs of social enterprises, at their different stages of development. There is an immediate need to examine both the demand for and the supply of finance for social enterprises. On the demand side, any such assessment would need to consider both the needs for finance along the whole life cycle - from start-up through to consolidation and growth stages - and the type of capacity building support required to ensure investment readiness among these organisations. It is also important to consider whether there is sufficient and appropriate supply of finance for social enterprises and social ventures more broadly, and whether financial intermediaries, social finance providers and public bodies could play a greater role. Taking a holistic approach could help to fill financing gaps and ensure a pipeline of financially sustainable and investible social enterprises. A number of opportunities exist for companies in Estonia, in particular for start-ups and SMEs and an alternative financing market is slowly emerging that could benefit social enterprises. Despite that, social enterprises, in particular in the form of non-profit organisations, still face a number of challenges to access financial markets and become more financially sustainable. This section explores the strengths and challenges of the Estonian landscape when it comes to access to finance for social enterprises, by addressing both the demand and supply perspectives. It then provides recommendations to better map the needs and provision of finance, remove legal barriers and promote a social investment market to facilitate social enterprises' access to finance.

\section{Strengths}

\section{Start-up grants for entrepreneurs}

Entrepreneurs can apply for start-up grants worth up to EUR 15000 through the State Shared Service Centre and RDCs offer advisory services. ${ }^{21}$ This facility is open to any start-up that is less than 24 months old and self-financing must account for $20 \%$ of the total cost of the project. There is no equivalent start-up grant for non-profit associations. Social entrepreneurs may also apply for a start-up grant worth up to EUR 4474 from the Unemployment Insurance Fund. ${ }^{22}$ This grant is for unemployed people, with sufficient

\footnotetext{
${ }^{21}$ For more information, please see: https://www.arenduskeskused.ee/en/about/

22 For more information, please see: https://www.tootukassa.ee/eng
} 
experience, education or training, to set up their own enterprise. ${ }^{23}$ This grant must be used to set up a company and cannot be used to establish a non-profit association. In both cases, however, any social entrepreneur wishing to use the legal form of a private limited company may apply for these grants.

\section{Favourable conditions for SME lending}

Most social enterprises may be identified as SMEs. It is therefore important to understand the financing landscape for this type of organisation. Business lending to SMEs fell by roughly $50 \%$ during the financial crisis from EUR 3.6 billion in 2007 to EUR 1.87 billion in 2010, and even though lending has risen since the recovery, lending remained below pre-crisis levels in 2017 at EUR 2.55 billion (OECD, 2019[44]). Under the Estonian corporate income tax system, all reinvested profits are tax-free. As such, there is an incentive for companies to reinvest their profits, which could partly account for the relatively low demand for loans. In comparison to the EU average, Estonia has relatively low levels of bankruptcies, and low levels of nonperforming loans (European Union, 2017[45]). Access to finance is not seen as a hurdle to business growth. Indeed, most firms are satisfied with the type, amount, cost and maturity of the funding received. Access to finance is only identified as an issue for $5 \%$ of Estonian SMEs, compared with $7 \%$ at the EU level (European Union, 2019[46]).

\section{Availability of starter loans, loan guarantees, subordinated loans and micro-loans}

Established by the Ministry of Economic Affairs and Communications in 2002, KredEx is a public-private cluster raising awareness about the Estonian financial sector and providing a range of financial products to businesses and citizens:

- Between 2008 and 2018, it provided starter loans to 500 companies, creating more than 1900 jobs. ${ }^{24}$ These loans have lower collateral requirements and demand fewer guarantees than mainstream banks.

- KredEx also provides loan guarantees for SMEs looking to raise external funding but lacking collateral and self-financing. With funding from the European Regional Development Fund (ERDF), KredEx gave loan guarantees to nearly 3500 companies between 2001 and 2016, enabling these companies to access EUR 1.4 billion, creating 12000 new jobs. ${ }^{25}$ The total number of guarantees issued during this period was EUR 632 million, supporting EUR 1.2 billion worth of loans (OECD, 2019[44]) Between 2015 and 2018, the COSME agreement signed between KredEx and the European Investment Fund (EIF) enabled KredEx to support 1000 Estonian SMEs with EUR 200 million worth of loans and leases (OECD, 2019[44]).

- Micro-loans worth up to EUR 25000 with guarantees from the EIF and the European Programme for Employment and Social Innovation (EaSI) are also available from LHV Pank ${ }^{26}$, Swedbank ${ }^{27}$ and SE Capitalia ${ }^{28}$. These micro-loans are aimed at young entrepreneurs, ethnic minorities and entrepreneurs with limited access to credit.

- In addition, KredEx has been providing subordinated loans since 2011 with funding from the ERDF, to help fast growing companies that lack the guarantees or self-financing needed to obtain a bank loan. Subordinated loans provide companies with capital in order to raise their level of selffinancing which enables them to access other sources of finance (OECD, 2019 [44]).

\footnotetext{
${ }^{23}$ For more information, please see: https://www.tootukassa.ee/eng/content/subsidies-andbenefits/business-start-subsidy

${ }^{24}$ For more information, please see: https://kredex.ee/en/financing-companies/starting-companies

25 Ibid.

${ }^{26}$ For more information, please see: https://www.lhv.ee/en/

27 For more information, please see: https://www.swedbank.ee/private?language=ENG

${ }^{28}$ For more information, please see: https://www.capitalia.com/en
} 
It is difficult to determine precisely how many of these SMEs could be identified as social enterprises along the entrepreneurial continuum; however, it could be assumed that social enterprises that operate like SMEs are able to benefit from these facilities.

\section{Growing venture and growth capital markets}

The Baltic investment ecosystem, which includes accelerators, seed and early stage VC growth and buyout funds, is vibrant and growing (ESTVCA, 2018[47]). In 2012, the Baltic Innovation Fund (BIF), a fund of funds, was set up by Estonia, Latvia, Lithuania, and the EIF to stimulate the development of venture capital markets in the Baltic States. Between 2013 and 2016, the BIF invested EUR 130 million into private equity and venture capital funds in the Baltic States, which were matched by private investors and pension funds. ${ }^{29}$ In 2016, the EstFund was set up by the EIF and the Estonian Government with funding from the ERDF, with the aim of attracting venture capital investments in Estonian SMEs. ${ }^{30}$ EstFund has made investments of EUR 60 million into venture capital funds in total, which have been supplemented by private investments worth up to EUR 40 million. Two new funds were added to the programme in 2018 (OECD, 2019[44]).

In the last few years, Estonian companies have successfully attracted venture and growth capital. In 2016, EUR 106 million was invested in 43 companies, EUR 272 million in 40 firms the following year and in 2018 EUR 328 million in 30 companies. ${ }^{31}$ The largest investments in 2017 and 2018 were EUR 240 million in TransferWise and EUR 150 million in Taxify respectively. ${ }^{32}$ There is no data on how many Estonian startups have a primarily social or environmental objective, and could therefore be identified as a social startup. However, it is currently estimated by Startup Estonia that nearly $20 \%$ of the companies they work with have a social or environmental objective. ${ }^{33}$ For social start-ups that can demonstrate high growth potential, there is a thriving and growing investment ecosystem from which they could benefit.

\section{New financing opportunities for social enterprises}

Although social enterprises which are organised as non-profit associations cannot apply for start-up grants from the State Shared Service Centre or the various loan facilities available to private limited companies, there are a few potential sources of funding. One such opportunity is presented by Estonia's vibrant alternative finance market. ${ }^{34}$ In 2017, Estonia was ranked second in Europe for alternative finance volumes per capita and $13^{\text {th }}$ in terms of total volumes (Tana Ziegler et al., 2017[48]). Given the size of Estonia's population, this is notable. There are now a wide range of crowdfunding platforms operating in Estonia including: Hooandja ${ }^{35}$, a donation based crowdfunding platform; Bondora ${ }^{36}$, a P2P lending platform for personal loans; Fundwise ${ }^{37}$, an equity based crowdfunding platform and; Funderbeam ${ }^{38}$, a secondary market for venture capital. A number of social enterprises have secured funding using these platforms. For

\footnotetext{
${ }^{29}$ For more information, please see: https://www.eif.org/what we do/resources/BIF/index.htm

${ }^{30}$ For more information, please see:https://www.kredex.ee/en/news/eif-and-kredex-launch-eur-60m-estfund

${ }^{31}$ For more information, please see: https://www.startupestonia.ee/blog/2018-records-for-the-estonianstartup-sector-new-wave-of-entrepreneurs-in-the-community

32 Ibid.

33 This was a point raised by informants during the OECD study visit.

34 The term "alternative finance" describes the channels or instruments that have emerged in the past few decades beyond the scope of the traditional finance system to facilitate the provision of loans, investments and donations. Channels for alternative finance include crowdfunding and peer-to-peer lending. Instruments include cryptocurrencies such as Bitcoin and Ether, Social Impact Bonds and community shares.

35 For more information, please see: https://www.hooandja.ee/

${ }^{36}$ For more information, please see: https://www.bondora.com/en

${ }^{37}$ For more information, please see: $\mathrm{https}$ ://fundwise.me/

${ }^{38}$ For more information, please see: $\underline{\text { https://www.funderbeam.com/ }}$
} 
example, Minutes of Stillness ${ }^{39}$, which promotes mindfulness in schools, raised EUR 11068 using Hooandja to develop a handbook for parents. ${ }^{40}$ Although P2P Consumer Lending and P2P Property Lending are the most popular models by total volumes (Tana Ziegler et al., $2017_{[48]}$ ), the growth of the alternative finance market could provide new financing opportunities for social enterprises.

Another potential source of funding for social enterprises is the Good Deed Foundation. ${ }^{41}$ Set up in 2003 to promote social entrepreneurship, the GDF provides venture philanthropy to both social enterprises and non-profit organisations. It currently has two funds: The Impact Fund that aims to help 4 to 6 high impact initiatives to scale up with EUR 500000 over three years; and The Education Fund which aims to support 10-15 initiatives working in the field of education with a total investment of EUR 1 million. The GDF has supported a wide range of social enterprises and initiatives, most notably the re-use centres Uuskasutuskeskus ${ }^{42}$ and Kiva School ${ }^{43}$, a nationwide anti-bullying programme.

\section{Challenges}

\section{Financial sustainability remains a challenge for many social enterprises}

Recent research undertaken by ESEN has highlighted a number of challenges faced by social enterprises. Its members, which are mostly non-profit associations, report problems in developing financially sustainable business models and a lack of resources for accessing specialist support services, as well as developing their products and services and covering their running costs. ${ }^{44}$ These challenges are particularly acute for those social enterprises whose main client is the Government: public procurement contracts are organised on such a short-term basis that, in practice, social enterprises work on a projectto-project basis and are therefore unable to develop sustainable revenue streams. ${ }^{45}$

\section{Non-profit social enterprises cannot access mainstream financial support schemes}

All business support programmes exclude non-profit associations and foundations, which is problematic since the vast majority of officially recognised social enterprises in Estonia (as many as 93\%) are nonprofit associations (European Commission, 2019[13]). Indeed, social enterprises that are non-profit associations are unable to apply for starter loans, loan guarantees or subordinated loans from KredEx, start-up grants from the State Shared Service Centre, the micro-loans that are available via the EaSI programme or any of the financial support programmes offered by Enterprise Estonia. Moreover, Enterprise Estonia and KredEx focus their support on SMEs with export potential. This criterion may prove problematic for social enterprises that are SMEs but that focus on meeting local needs (such as WISEs).

\section{Challenges facing non-profits in obtaining bank loans and bank guarantees}

Since non-profit social enterprises cannot access mainstream support schemes, they have to resort to conventional bank loans to meet their capital needs. However, negative perceptions of non-profit organisations can act as a barrier. It is a common perception amongst mainstream financial providers that social enterprises do not generate sufficient revenue to pay back loans, have no cash-flow from market

\footnotetext{
${ }^{39}$ For more information, please see: http://vaikuseminutid.ee/

${ }^{40}$ For more information, please see: https://hooandja.ee/projekt/toeta-laste-keskendumisharjutuste-kasiraamatu-jaapi-valjaandmist

${ }^{41}$ For more information, please see: https://www.heategu.ee/en

42 For more information, please see: https://uuskasutus.ee/en/

43 For more information, please see: http://www.kivaprogram.net/estonia

44 ESEN, qualitative in-depth interviews with social enterprises, January-February 2019, The Social Enterprise Network, 2019.

45 lbid.
} 
income and therefore have limited growth and export potential (Nordic Council, 2018[49]). Banks therefore ask for extra guarantees from social enterprises established as non-profit associations, such as personal guarantees, which is not necessarily required for private limited companies. In some cases, it can be difficult to secure a loan without collateral, usually in the form of physical assets owned by the non-profit association (Nordic Council, 2018[49]). One of the major consequences of these additional requirements for lending is the prevalence of bootstrapping, the use of internal finance sources (e.g., personal savings, the cash coming in from the first sales) to meet the needs of a business without relying on external finance (Winborg and Landström, 2000 ${ }_{[50]}$ ). It is important to note that requirements for collateral have been raised as an issue for SMEs, with 35\% of Estonian SMEs reporting that collateral requirements are the most significant limiting factor in getting external finance, versus $12 \%$ in the EU on average (European Union, 2019[46]).

\section{Lack of social investment market}

Social investment is "the provision of finance to organisations addressing social needs with the explicit expectation of a measurable social, as well as financial, return" (OECD, 2015[51]). The social investment market in Estonia is embryonic. Currently, only one social lender, the Good Cooperation Savings and Loans Association (GCSLA) ${ }^{46}$, set up in 2015, provides deposits and loans to social enterprises who are its members. In the last two years the GCSLA has financed 20 projects, with an average deal size of EUR 10000 , due to limited funding capacity. However, some social enterprises, such as Triumf Health ${ }^{47}$, have been able to access traditional venture capital in the absence of a social investment market. There is a lack of data about how many social start-ups may be securing investment in this way. It is also unclear whether and to what extent the use of the non-profit association legal form may be hampering both the demand for and the supply of social finance. Although, quasi-equity models such as revenue participation schemes could be used to overcome such obstacles, it is clear that there is both a weak demand for and supply of social investment (Nordic Council, 2018[49]).

In addition, recent research has pointed to a widespread lack of understanding about the role and benefits of social impact investing and a lack of skills and capacity to develop a social investment ecosystem (Nordic Council, 2018[49]). The weak demand for social investment may be due to different elements: a perception amongst some social enterprises that they are non-governmental organisations rather than social businesses; a dependence on grants and a lack of experience in securing investments; risk-averse mindsets and; the lack of skills required to lead and grow a financially sustainable social business (Nordic Council, 2018[49]). There is also a weak culture of social impact measurement, which may also be stifling the development of the social investment market. Without recognised and shared measures of social impact, it is difficult for social investors to gauge the full value of a particular social enterprise or to benchmark a potential investment in a social enterprise against others. In general, however, there is insufficient information on the financing requirements of social enterprises, along the entrepreneurial continuum, and at each stage of the life cycle. In particular, data about the demand for social finance by social enterprises is lacking, including the number of investment ready social enterprises that require growth capital.

\section{Policy issues}

\section{Understanding the financing needs of social enterprises across the life cycle}

Social enterprises go through different stages from inception to impact. These stages of development are known as the life cycle of social enterprises. There are numerous life cycle models, but it is possible to

\footnotetext{
${ }^{46}$ For more information, please see: https://heakoostoo.ee/eng/

47 For more information, please see: $\underline{\text { https://triumf.health/ }}$
} 
identify four stages: seed, start-up validation, early scaling and dissemination (Santos F., Salvado J.C., de Carvalho I.L., 2013[52]). The financial instruments used and the financing requirements of social enterprises will differ at each stage.

\section{Box 3. Financing the social enterprise life cycle}

At the seed stage, social entrepreneurs usually develop a business plan, outlining their business model, social value proposition, and how their venture will address the needs of their beneficiaries. Up to EUR 50000 is typically required at this stage and is usually raised through bootstrapping or from Friends, Family and Fools (3Fs).

At the start-up validation stage (typical financing needs of EUR 50000 - EUR 250 000) social entrepreneurs will usually test their idea in practice through pilots, trials or prototypes. These experiments test working hypotheses, generate evidence of impact or provide feedback, which can be used to refine or further develop the product or service. Funding is usually provided at this stage by the 3Fs (typically loans or donations), or by philanthropic organisations in the form of non-repayable grants. It is estimated that the greatest financial need is at seed and validation stages. There is potentially a key role here for individual investors, either through crowdfunding platforms, community shares or networks of angel investors.

The early scaling stage involves putting the organisation on a sound financial footing. Depending on the type of social enterprise and its field of activity, this could include deploying a service, establishing supply chains, setting up internal systems and processes, purchasing equipment and assets, hiring talent, securing contracts and customers, and developing a marketing and communication strategy. At this stage, social entrepreneurs typically need between EUR 250000 and EUR 1.5 million, often for working capital or to purchase property or equipment.

The dissemination stage (typical financing needs of EUR 1.5 million and above), which is also known as "scaling up" or "scaling out," may involve extending services to new territories or new markets, developing new and complementary services or products, or growing the team to service greater demand. Social investors play a critical role in these early scaling and dissemination stages. Social lenders (such as credit unions or ethical banks), social investment funds and venture philanthropy funds can provide a range of financial instruments to meet the needs of social enterprises. These investments can be in the form of equity, debt, grants or hybrid models that incorporate two or more elements. The most common form of investment is a loan, which can either be secured against an asset, or unsecured and usually therefore more expensive.

Source: (OECD, 2019[53])

It is very rare for social enterprises to enjoy sufficient and suitable funding from the very earliest stages of development, all the way to scaling up and dissemination. Indeed, it is very common for social investment markets to experience financing gaps. Such gaps can include a lack of funding for particular stages of development, a lack of specific types of financial instruments, a lack of providers, or a lack of liquidity because there is no secondary market for trading shares.

One common problem for social enterprises is known as "Death Valley", which is a term used in venture capital to describe the time between when a start-up receives its first capital investment and when it starts generating revenues. This is when start-ups are most vulnerable to cash-flow problems. In the context of social enterprises, there can be a lack of funding for social enterprises to get through this period of consolidation. In Central Europe, NESsT identified that social enterprises face a scarcity of funding 
amounting to EUR 100000 during that transition period. Similarly, Impact Hub in Milan found that this financing gap amounts to EUR 100000 - 200 000, while Impact in Motion in Germany found a lack of capital amounting to EUR 100000 - 500000 range for social enterprises in their consolidation stage (Varga and Hayday, 2017[54]). There is currently no data on where this "Death Valley" occurs for Estonian social enterprises.

Because all social investment markets differ, it is essential to carry out an assessment, before considering the development of specific instruments or the creation of new funds or bodies. Such an assessment will provide a clear overview of the specific needs of social enterprises at each stage of the life cycle, as well as the existing provision of finance. Given the size of the Estonian market, and since there is a lack of clarity over the size of the social enterprise sector, any such assessment should include all organisations with a primarily social or environmental objective. This could include, for example, non-profit associations that generate revenue from selling goods or services as well as social start-ups.

\section{Building a social investment market}

Social investment is defined in a variety of ways. Broadly, it means the provision of finance, which is at least nominally repayable and accepts below market returns in the pursuit of a social, cultural or environmental goal. In addition, social investors seek to measure the social impact generated by investees, and will often provide non-financial support (such as coaching, training or advice), in order to mitigate risks, and maximise social and financial returns. Social investment should be understood as operating along a continuum from "finance first" where the primary goal is to generate financial value (this would include mainstream venture capital funds or investment funds), all the way to "impact first" investors where the primary goal is to generate social value (this might include foundations or venture philanthropy organisations which provide non-repayable grants with capacity building support). Social investment funds and social lenders will want a blend of both social and financial returns.

Figure 1. Investment spectrum

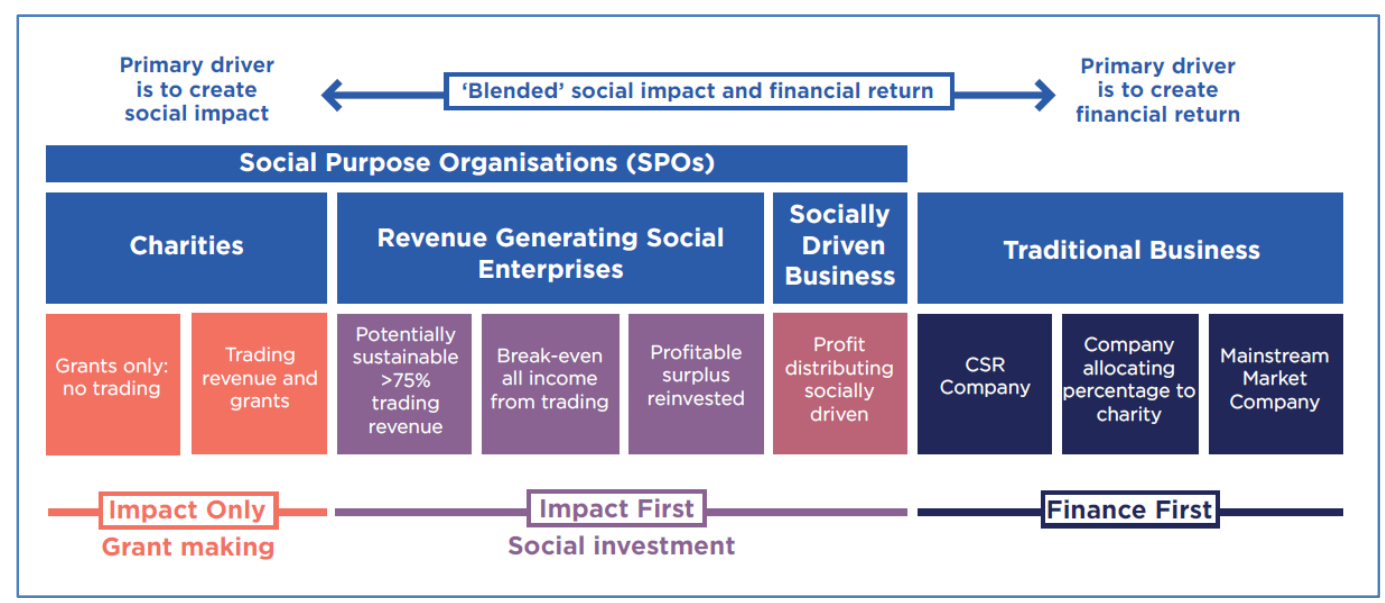

Source: (European Venture Philanthropy Association, 2018[55])

A well-functioning social investment market requires three elements to be in place:

- supply of social investment;

- demand for social investment from social ventures; 
- intermediaries that are able to link supply and demand.

Intermediaries can act in many ways. They can provide investment readiness or capacity building support to help social ventures access social finance, they may facilitate deals between investors and social ventures, or raise awareness about social investment among social enterprises or about the benefits of investing in social enterprises among potential investors.

One example is the Financing Agency for Social Entrepreneurship (FASE) in Germany, set up in 2013 to address the mismatch between the demand and supply for social finance. ${ }^{48}$ FASE works closely with early stage social enterprises to help them raise growth capital by providing investment readiness support, access to investors and by designing innovative financing schemes tailored to the needs of investors and social enterprises.

It is essential to align measures intended to promote the development of a social investment market with that market's stage of development (Varga and Hayday, 2017[54]). For example, for nascent social investment markets the main goals may be to simply raise awareness of social investment on both the supply and demand side, build a social enterprise pipeline with a particular focus on early stage ventures, help to create an enabling environment and trial the first use of social investment. For young social investment markets, it might be more appropriate to focus on capacity building, increasing resources, building networks, and testing various models. Meanwhile, for more advanced social investment markets, the objective may be to develop the social enterprise pipeline with a particular focus on scaling and growth stages, disseminating evidence of social impact, ensuring a variety of support services and financial instruments, widening the pool of ecosystem players and ensuring the provision of integrated support (financial and non-financial) along the social enterprise life cycle (Varga and Hayday, 2017[54]).

Social investors typically invest in later stages of the life cycle, once a social enterprise has a sustainable business model and/or a solid performance history. One of the most common complaints among social investors is the lack of high-quality investment opportunities with a proven track record (Saltuk et al., $2014_{[56]}$. These investors need a large and steady pipeline of potential investees, which is why most support organisations (namely those providing grants, advice and training) focus on the seed and start-up validation stages. Creating a large pool of early stage and start up social enterprises is therefore one way of increasing demand for social investment.

Providing capacity building and investment readiness support is one way of increasing the pool of investible social enterprises. This could be provided through one-to-one mentoring and coaching or through group training programmes such as incubators and accelerators (see Section 6). Another approach is to provide small grants, through either traditional small-grant programmes or awards and competitions. The latter usually invite a wide range of submissions through an open call, which can be an effective way of uncovering new ideas. When coupled with capacity building support, awards and competitions can be an effective way of identifying and supporting social enterprises with high-growth and high-impact potential, and thereby build an investment pipeline. UnLtd, the UK's foundation for social entrepreneurs, is one example of such an approach. UnLtd has played a critical role in the development of the social investment market in the UK, largely by creating a pipeline of social enterprises through the provision of early stage grants and repayable growth finance, but also award prizes or business advice. The model has now been replicated internationally with UnLtd in Thailand, India and South Africa.

\section{Box 4. UnLtd}

UnLtd was set up in 2002 with a GBP 100 million endowment to promote social entrepreneurship. It offers a range of awards and prizes for social entrepreneurs to develop test and grow their social

${ }^{48}$ For more information, please see: https://fa-se.de/en/ 
ventures. These cash prizes are coupled with networking opportunities and varying levels of mentoring, business advice and opportunities for skills development. The income generated from the endowment is used to fund the award programmes. The main awards offer between GBP 500 and GBP 15,000 across three separate schemes:

Try It Awards (up to GBP 500) to develop an idea and demonstrate proof of concept, access the UnLtd Mentor Scheme as well as a range of networking events.

Do It Awards (up to GBP 5,000) to set up and establish a social venture and start to demonstrate some social impact. As part of the package, social entrepreneurs receive bespoke support from an UnLtd adviser, access to mentors as well as networking and training events.

Grow It Awards (up to GBP 15,000) for social entrepreneurs who have developed a business model that works. Award winners receive 12 months mentoring and tailored support from UnLtd, access to training workshops, networking events and introductions to potential investors.

In recent years, UnLtd selected winners according to three priority areas: building access to employment, resilient communities, and solutions for an ageing society. Winners can then be directed to UnLtd's accelerator programme "Thrive" or to its Impact Fund, which provides up to GBP 150,000 in repayable finance and bespoke one-to-one support. In 2017-2018, the average value of the awards was GBP 6,450. In the same year, UnLtd supported 335 social entrepreneurs across all its programmes (253 in the idea development and start-up stages and 82 in the growth stages).

Source: https://www.unltd.org.uk/

In order to mitigate risks and maximise both financial and social returns, it is essential that social enterprises are able to access both financial and non-financial support. Moreover, the types of support required will vary over time. For example, at the start-up and early scaling phases, social enterprises require support in developing sustainable business models and improving their internal systems and processes. Meanwhile, at the growth and dissemination stages, support might focus on investment and contract readiness, to ensure that social enterprises are able to take on the investment they need to grow

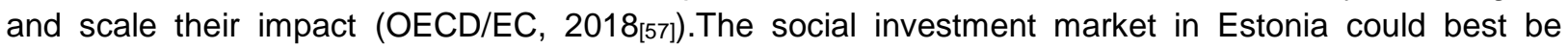
described as embryonic. Therefore, before considering the use of specific instruments (e.g. Social Impact Bonds), it may be beneficial to consider laying the foundations of a social investment market by: raising awareness about the benefits and role of social investment; supporting social enterprises to better measure their social impact; starting to build a pipeline of investible social enterprises by providing early stage and start up social enterprises with financial and non-financial support; and trialling the first use of repayable finance for social enterprises.

\section{Recommendations}

\section{Carry out an assessment of the financing needs of social enterprises}

There is a lack of knowledge around the specific financing needs of social enterprises. There is also insufficient knowledge about the provision of finance for such organisations. Given the small number of self-identified social enterprises, and questions about the accuracy of the statistical efforts to date, to map the size of the sector, it is important that any such assessment includes organisations which, whilst not social enterprises per se, share many of their characteristics. This would include, for example, non-profit 
associations that de facto generate revenues by selling goods and services, SMEs and start-ups that have a primarily social or environmental objective and socially responsible businesses. This assessment should consider the provision of finance to social enterprises as well as the kind of capital requirements of social enterprises at seed, start-up, consolidation and growth stages.

\section{Remove legal barriers to ensure an equal access to financing opportunities and support for social enterprises and mainstream businesses}

Remove legal barriers to ensure that social enterprises that are non-profit associations are able to access the same financial support mechanisms as private limited companies. Instead of focusing on legal form, support organisations should consider whether an organisation has a solid business plan, the capacity to generate income and a sustainable business model. If social enterprises in the form of non-profit associations can meet these conditions, the following schemes could be made available to them:

- $\quad$ Start-up grants from the Unemployment Insurance Fund;

- $\quad$ Start-up grants from State Shared Service Centre;

- $\quad$ Starter loans and loan guarantees from KredEx.

\section{Set up an intermediary to act as a social investment market builder and make access to finance easier for social enterprises}

Establishing an intermediary is a necessary step to consolidate Estonia's social enterprise ecosystem. The intermediary could start to build a pipeline of social enterprises by focusing on the early stages of development. In the longer term, its role would be to help consolidate a social investment market in order to support social enterprise development. In the shorter term, its work could include:

- Distributing small grants or prize awards for social entrepreneurs to develop and test their ideas. These could be done in the form of an open call, focused on priority issues such as skills and education, workability, social inclusion, care for the elderly, etc.

- Providing capacity building support, alongside small grants. Such advice, training, coaching and/or mentoring should supplement the support already provided by RDCs and the NFCS.

- Trialling the provision of repayable finance, ideally leveraging investment from foundations and corporate investors. Findings from the aforementioned assessment should feed into the design of the specific instruments used. Depending on the type of instrument, authorities could also consider introducing risk-sharing mechanisms, such as guarantees, in the short term, to attract investors.

- Providing opportunities for networking, hosting events and raising awareness amongst investors and potential investees. These events should bring together stakeholders from different sectors and the Government to encourage both cross-sectoral and intra-sectoral links.

The new intermediary could be funded by the European Commission's Employment and Social Innovation (EaSI) Capacity Building Investments Window. The aim of this programme is to develop the institutional capacity of financial intermediaries that require capital for sustainability or growth. It also provides seed financing for the establishment of new intermediaries. This intermediary could also make use of other EaSI programmes designed to support social enterprises, namely the EaSI Guarantee and EaSI grants for the provision of business development services for at-risk groups (European Commission, 2018[58]). Another option is to consider the establishment of such an intermediary at the regional level, as a Baltic Social Enterprise Development Fund. If so, funding could be secured through the European Fund for Strategic 
Investments (EFSI), which supports investment in strategic projects in areas including education, innovation and support for small and mid-sized businesses, across Europe. ${ }^{49}$

${ }^{49}$ For more information, please see: https://www.eib.org/en/efsi/what-is-efsi/index.htm\# 


\section{Improving access to markets to promote social entrepreneurship and social enterprises}

Access to markets - public or private - represents an important source of revenue for social enterprises, notably in countries like Estonia where social finance is limited. Social enterprises, regardless of their legal form, harvest to a great extent their resources from the public market via public procurement, which represents $13 \%$ of the country's GDP and $35 \%$ of the state budget. Previous experience in attaining environmental objectives through public procurement can provide inspiration for promoting the use of social considerations in public contracts. This is particularly timely given the measures that Estonia has designed in order to implement the Welfare Development Plan 2016-2023 and attain its employment and welfare goals by procuring social value. At the same time, the private sector slowly but steadily recognises the importance of social and environmental impact and starts to test possible modalities of cooperation with organisations that aim to attain such impact through their activities. This section examines both the strong and challenging aspects of Estonia's public and private markets when it comes to facilitating the access of social enterprises to them, addresses the main policy issues emerging from this analysis, and provides some concrete and actionable recommendations.

\section{Strengths}

\section{A public procurement environment stimulated by the advanced use of technology and innovation}

Public procurement in Estonia represents a significant market with total value of approximately EUR 2 billion, $13 \%$ of the GDP and $35 \%$ of the state budget. At the same time, Estonia has leveraged the use of technology in order to streamline its public procurement procedures. In fact, the country has been at the forefront of electronic public procurement (e-procurement): in 2017, 93\% of the 10375 total number of procedures were carried out electronically. In addition, all relevant information regarding the course of these procedures are gathered in one place, the Public Procurement Register (Ministry of Finance, 2019[59]). The online portal of the Public Procurement Register aims to render public procurement fully transparent, streamlined and efficient in order to improve SMEs access to public contracts. More precisely, $87 \%$ of the total number of contracts in 2017 were awarded to SMEs, including social enterprises in the form of a limited liability company, compared to $13 \%$ of large enterprises. The register offers a wide range 
of possibilities both for procurers and bidders, such as organising e-tenders, finding new business opportunities, accessing guides for users, receiving notices, accessing contract information and reviewing committee's decisions (Public Procurement Register, 2018[60]). Some preliminary efforts have been undertaken to leverage this innovative procurement environment in order to tackle social challenges, including by procuring from social enterprises, upon the suggestion of the Social Innovation Taskforce that has been working under the Government Office since March 2016.

\section{On-going efforts to attain environmental objectives through public procurement}

Public procurement can be used strategically for attaining environmental objectives and the country has already taken some steps towards this direction. In 2006, a set of activities for promoting green public procurement (GPP) were introduced to the National Environmental Action Plan of Estonia for 2007-201350 in line with the environmental and sustainable public procurement priorities published by the Ministry of the Environment and with the Environmental Strategy 203051. Moreover, in order to promote GPP, the Government has been providing training sessions for local government officials and specialists from contracting authorities explaining the concept and procedures for an environmentally sound procurement. Currently, an electronic platform is under development to further streamline and enhance the uptake of the use of environmental criteria in public procurement. This experience can provide inspiration for procuring contracts with social considerations and for further improving the procurement environment for employment and social services delivered by social enterprises.

\section{Challenges}

\section{Lowest-price criterion still prevails in bidding offers}

Estonia still uses predominantly the lowest-price as the award criterion for public tenders. However, it has marked progress in using the assessment method of the most economically advantageous tenders (MEAT), which allows consideration of bidding offers based on criteria beyond the price (i.e. other qualitative, technical, sustainable aspects).Between 2009 and 2019, the method was used on average for $19 \%$ of tenders and with a pick to 27\% of tenders in 2017 (Ministry of Finance, 2019 [59]; European Commission, $\left.2019_{[3]}\right)$. Although some quality requirements and other impact considerations exist for contracts related to the provision of social services, commissioners seem to face difficulties in assessing quality and impact (OECD study visit, April 2019). For example, curriculum vitae are often used as a proxy for team qualifications, which are then used as a proxy for quality and impact, even though the causal relation between qualifications, quality and impact is far from being direct. Overall, the lowest-price criterion prevails and, in practice, most public services contracts are awarded to the bidding offers that fulfil this criterion.

\section{Multiple challenges persist for commissioning and delivering employment and social services}

The provision of employment and social care services for vulnerable groups represents an important market opportunity for social enterprises, which remains nonetheless largely untapped. Several policy initiatives, such as the Work Ability Reform and the Welfare Development Plan (2016-2023), highlight the importance of improving labour market outcomes and social inclusion for people from vulnerable groups. Public procurement has been put forth as one of the tools for attaining these objectives. The new Public

\footnotetext{
${ }^{50}$ For more information, please see: https://www.envir.ee/sites/default/files/keskkonnategevuskava inglisek.pdf

${ }^{51}$ For more information, please see: https://www.envir.ee/sites/default/files/keskkonnastrateegia inglisek.pdf
} 
Procurement Act ${ }^{52}$ (2017), which recently transposed the EC Directive $24 / 2014 / \mathrm{EU}^{53}$, offers the possibility to procure social value and to attain better labour market outcomes. The Directive thus creates opportunities for governments to "buy social" by determining contract award criteria, technical specifications and reserved contracts. This in turn opens up opportunities for organisations pursuing social objectives through the products or services they deliver, and/or by employing individuals from vulnerable groups, as it is the case for example for social enterprises.

As service providers, social enterprises work closely with two main sources for public contracts: the Unemployment Insurance Fund for professional work rehabilitation programmes and the Social Insurance Board for the social rehabilitation programmes. In this process, they face a twofold challenge. The first one is the difficulty to convince employers to accept the possibility to employ people with reduced work capacity. In an audit survey in 2017 , only $31 \%$ of the interviewed firms mentioned that they were willing to hire those with reduced work capacity, and $44 \%$ declared impossible to do so (National Audit Office of Estonia, $\left.2017_{[61]}\right)$. The second is the fact that social enterprises often in the form of non-profit organisations do not fully cover the needs of the beneficiaries. This can be explained by the fact that the services are designed with the social workers' skills in mind and not the needs of the beneficiaries (Browne et al., 2018[62]). At the same time, the fact that most of these organisations rely on short-term contracts questions their sustainability. This means that when the public contract ends, social enterprises may see their revenues drop substantially or completely. In turn, social enterprises may have to exit the market and cease their activities; decrease the number of employees; and/or offer short-term contracts, which lead to higher turnover of staff. This also hinders the continuity of the organisation's institutional knowledge and knowhow when it comes to navigating the bidding procedure.

\section{Few opportunities for up-skilling public sector commissioners and services providers}

Public sector commissioners and social enterprises have limited skills for procuring and bidding for contracts with social value. This lack of skills hinders them from making the best use of the relevant provisions included in the new Public Procurement Act ${ }^{54}$ (2017). This is notably the case of social considerations or reserved contracts for providers of services for the social and professional integration of persons with disabilities and disadvantaged persons, or for social enterprises in the form of non-profit organisations providing employment and social services. Despite the provision of training by the Ministry of Finance in order to raise awareness and improve the skills of contracting authorities - notably on environmental criteria - there does not seem to be many opportunities for public sector commissioners to develop their skills and capacities in procuring contracts with social considerations. Overall, despite the creation of the Social Value Guidelines in 2017 for contracting authorities, there is a general lack of expertise and tools associated with social public procurement but also with social impact measurement, which could be useful to assess bids.

\section{Partnerships with the private sector are scarce}

As much as there is increasing awareness that partnerships between mainstream businesses and social enterprises are vital for pursuing the necessary systemic changes in order to achieve the Sustainable Development Goals (SDGs), these are almost non-existent in Estonia. With $27 \%$ of Estonians willing to pay higher prices for the products and services of companies that contribute to the development of society through various activities (The Nielsen Company, $2013_{[63]}$ ) and with $70 \%$ of Estonians considering the impact of these companies on society to be positive (European Commission, 2013[64]), there is clearly a strong case for mainstream businesses in partnering with social enterprises, both from an inclusive

\footnotetext{
52 For more information, please see: https://www.riigiteataja.ee/en/eli/505092017003/consolide

${ }^{53}$ For more information, please see: https://eur-lex.europa.eu/legal-content/EN/ALL/?uri=CELEX:32014L0024

${ }^{54}$ For more information, please see: https://www.riigiteataja.ee/en/eli/505092017003/consolide
} 
business and supply chain perspective as well as from a reputational one. However, mainstream businesses seem to be reluctant to integrate social enterprises in their value chains. Vice-versa, social enterprises do not have the reflex of approaching mainstream businesses in order to provide them with their services or goods (B2B). They also tend to prefer the way of public contracts (especially if they are in the form of a non-profit organisation) or to reach out directly to consumers (B2C) (mostly when they are in the form of a limited liability company).

\section{Policy issues}

\section{Embedding social value in public procurement}

Social value has the potential to transform the way in which goods and services are commissioned by public authorities while creating additional social, economic and environmental benefits. Considering the potential of social value in public procurement can generate long-term savings by tackling social challenges with deeply rooted causes, such as social exclusion and unemployment of the most vulnerable. This requires making decisions for awarding contracts beyond focusing on short-term savings and based solely on financial grounds by selecting the bidding offer with the lowest-price. Social enterprises are well-placed partners for delivering services and goods while generating social value and impact, which is in the core of their mission. Moreover, they have the capacity to tailor their services to the beneficiaries' and the communities' needs and in some cases introduce innovative and agile solutions, which the public sector would not have had the expertise to develop or deliver otherwise (SEFORïS, 2017[65]). In some countries, like Spain, local authorities took the initiative to generate social value through their procurement ahead of the transposition of the EC Directive 2014/24/EU at the national level. In this process, they established the Mixed Commission for Socially Responsible Public Procurement and engaged with multiple relevant stakeholders in order to ensure sustainability and sound implementation (see Box 5). 


\section{Box 5. Barcelona City Council Decree for Socially Responsible Public Procurement}

Designed and implemented by the Barcelona City Council, the Municipal Decree 4043/13 for Socially Responsible Public Procurement aims to turn public procurement into an effective instrument serving the most vulnerable people in society. With this Decree approved in March 2013 and implemented in December 2013, social and environmental considerations became a guiding principle for municipal contractual activity. Barcelona City Council now requires its contracting bodies to ensure the incorporation and application of mandatory social and environmental clauses by making use of reserved contracts and social and environmental considerations in award criteria and contract performance clauses. The use of reserved contracts and the inclusion of social and environmental clauses are considered to be the rule, and not the exception.

The initiative originated from the Department of Quality of Life (covering social services), but was developed across different municipal areas involving experts from various fields (e.g. legal and accounting services, social services, economic promotion and equality, and construction). The drafting and approval process involved intensive dialogue and concertation. More than 50 people from 40 different governmental, corporate and social organisations (e.g. employers' associations and trade unions), as well as non-state actors (e.g. non-profit entities, solidarity organisations and social enterprises) worked together within the newly constituted Mixed Commission for Socially Responsible Public Procurement to draft the legal text until a consensus was reached. The Decree had strong backing from the Mayor's Office and was unanimously ratified at the end of a yearlong process by the Municipal Council, with the approval of all political parties. The Council's ability to reach a consensus represents considerable value added, and offers greater sustainability and legitimacy

It has the dual effect of allowing public authorities to make progress in combating social vulnerability, as well as connecting and establishing synergies between social and financial actors. It is a significant legal step affecting all public procurement in the City of Barcelona, with the result that more than EUR 500 million from the municipal budget allocated to construction work, services and supplies are now being used to advance social cohesion.

Source: (OECD/EU, 2017[66]) and https://www.betterentrepreneurship.eu/en/node/32

\section{Developing the skills of public sector commissioners for procuring social value}

Public sector commissioners often struggle to understand concretely what is a "socially preferable" good or service and how to evaluate it during a tender process. Dedicated whole-of-government purchasing guidance material could encourage and facilitate the Government departments and agencies to include social considerations in the procurement and open-up opportunities to social enterprises. In 2019, the Cabinet Office (UK) developed the Outsourcing Playbook ${ }^{55}$, a central Government guide on outsourcing decisions and contracting. This guide was jointly developed by the central Government and the suppliers, including social enterprises. It provides guidelines, rules, and principles that apply throughout the procurement life cycle. It also presents good practices from across the Government and discusses different approaches for commissioning public services. In addition, the UK Social Value Taskforce created the Social Value Maturity Index ${ }^{56}$. This is an online self-assessment and learning tool, which aims at helping both the public sector commissioners and the services providers to assess and monitor where they stand

\footnotetext{
${ }^{55}$ For more information, please see: https://www.gov.uk/government/publications/the-outsourcing-playbook

${ }^{56}$ For more information, please see: https://socialvalueportal.com/social-value-maturity-index/
} 
in terms of embedding social value in the way they deliver services and provide concrete guidance on how to do so.

Moreover, budget officers and administrators may not have the required skills that would allow them to proceed effectively. The provision of technical support and training to budget officers and administrators can help them to develop the necessary skills for incorporating social considerations to public procurement. Training can be provided by entities that know social enterprises well and, therefore, can help public sector commissioners to understand the nature and the needs of social enterprises. For instance, the SAW-B ${ }^{57}$ association in Wallonia, Belgium, organises training courses both for local contracting entities for implementing social considerations and for social enterprises (more specifically, for WISEs) and brings together supply and demand for socially preferable goods and services.

Finally, workshops and regular meetings for exchanging good practices with other administrations can be a source of inspiration and expertise. For example, the Procura network ${ }^{58}$ brings together European public authorities and regions and stimulates knowledge sharing. Similarly, in France, the Réseau Grand Ouest ${ }^{59}$ (RGO) is a large network of public authorities from the West of France comprised of specific working groups, which meet regularly and exchange good practices and case studies regarding tender criteria, market activities, and measuring and reporting methods.

\section{Building mutually beneficial partnerships and enhancing the role of social enterprises in sustainable value chains}

Social and environmental challenges cannot be resolved by the public sector, businesses or social enterprises alone. Building partnerships can be mutually beneficial for all actors and can allow tackling these challenges more effectively, from different angles, and eventually at larger scale. When working with social enterprises, mainstream businesses can access expertise and knowledge that it may not be possible to grow fast internally. For example, a few years ago, Coca-Cola decided to cut the water used to make a litre of Coke from more than three litres to 2.5 litres. However, it was overlooking the 200-plus litres it took to grow the sugar that went into that Coke. The company found that out because it partnered with the World Wildlife Fund (WWF), a non-profit organisation, which knew how to analyse the water footprint of the value chain. ${ }^{60}$ At the same time, social enterprises not only generate revenues when they are part of the value chain of a mainstream business, by providing their services or products, but they are also exposed to different organisational cultures that can help them enhance their business acumen and skills.

Mainstream businesses also enjoy positive reputational effects in terms of attracting, retaining, and engaging motivated employees, and of building trust and loyalty among consumers. Millennials are the driving force of this trend, both as employees and as consumers, with $86 \%$ of them claiming that business success should be measured in terms of more than just financial performance (Deloitte, 2017[67]). Lastly, partnerships between mainstream businesses and social enterprises can offer job opportunities and improve the well-being of people, who would had been excluded from the labour market otherwise (for an example, see Box 6).

\footnotetext{
57 For more information, please see: https://read.oecd-ilibrary.org/industry-and-services/boosting-social-enterprisedevelopment/saw-b-a-training-and-advisory-services-federation-belgium-wallonia-brussels 9789264268500-6en\#page1

58 For more information, please see: http://www.procuraplus.org/

${ }^{59}$ For more information, please see: https://reseco.fr/

${ }^{60}$ For more information, please see: https://www.worldwildlife.org/partnerships/coca-cola
} 


\section{Box 6. Specialisterne \& SAP: A partnership to access the market}

While people with autism spectrum disorder (ASD) have unique skills - for example, an outstanding memory or a remarkable eye for detail, a structured way of working, the ability to think outside the box and perform repetitive tasks with ceaseless enthusiasm - they struggle with social interaction and personal communication.

Specialisterne ("The Specialists") is a social enterprise established in Denmark in 2004 to pioneer new ways of harnessing the untapped skills of people with ASD and empower them by matching them with businesses in need of information technology (IT) experts. An impact assessment of Specialisterne concluded that its consultants have become valuable contributors to the labour market and solid taxpayers, less reliant on social welfare contributions. In 2008, Specialisterne Foundation (SPF) was established to scale the Specialisterne model and impact, with the objective of creating one million jobs globally for people with ASD by 2025. To this end, it has developed partnerships with international IT firms, marking a big step forward in creating decent workplaces for people with ASD, and setting standards for their recruitment and on-boarding.

As Specialisterne understands how best to recruit, train and retain new employees with autism, SPF and SAP partnered to create the "Autism at Work Programme". This joint experience has clearly demonstrated that partnerships between public sector organisations, innovative companies and social enterprises can boost quality job creation for people with ASD. Indeed, the involvement of public sector institutions at all levels (local, regional, national and European) brings crucial advantages: these institutions can provide funding to conduct feasibility studies and develop (local/regional) strategies, use social clauses in public procurement procedures to benefit employers of people with autism or similar disadvantages, assist in identifying and training talented young people with autism, and support awareness-raising efforts.

Source: (OECD/EU, 2017[66])

\section{Recommendations}

\section{Develop a training action plan on procuring social value}

Although a few training material for procuring social value, such as the Social Value Guidelines, are available in Estonia, additional actions are needed in order to leverage the possibilities that the new Public Procurement Act (2017) and the Welfare Development Plan (2016-2023) offer for including social considerations in public procurement. The Social Innovation Taskforce, if re-established as suggested in Section 2, and given its inter-ministerial composition, would be well placed to undertake this mission. Firstly, it could undertake a survey across the relevant ministries in order to identify the training needs of officials for procuring social value. Based on the results, a training action plan could be developed. This action plan should anticipate a diversity of the experience and expertise profiles of officials. More precisely, it could develop training curricula for three levels: 1 ) beginners - focusing on newcomers or officials dealing with social considerations in procurement rarely or occasionally, 2) intermediate - providing training to officials who are regularly exposed to these social considerations, and 3) advanced - targeting officials who need extensive expertise on them.

Training curricula could be structured not only based on the needed level of expertise but also depending on the officials' roles in public procurement. Two broad functions can be distinguished in this regard: officials carrying out procurement operations and officials controlling or reviewing procurement procedures. 
The latter group would require specific training to be able to better identify the different organisations in the social impact field, notably by raising awareness about the official definitions of social innovation, social entrepreneurship and social enterprises if/when adopted by the Government. Specific training on impact measurement methodologies would also be needed to be able to assess the bids more efficiently. Distance and online learning elements could be developed along with a certification process for officials. Clear identification of trainers would be essential for the success of the implementation of the training action plan. To this end, the Social Innovation Taskforce could, if re-established, develop a pool of trainers who deliver trainings on social considerations in public procurement. Lastly, it should develop a monitoring mechanism of the implementation of the training action plan. Similarly, training needs of social entrepreneurs bidding for public contracts could be identified and the training curricula could be adapted to their needs and stage of development.

\section{Create a knowledge-sharing group among the ministries dealing with sustainable procurement}

Establishing a group of officials from different ministries who deal with sustainable procurement could complement formal training programmes and stimulate knowledge-sharing and peer-to-peer learning to implement social and/or environmental considerations. For example, the Ministry of Environment has developed know-how for procuring green services and goods. Transferable lessons on how they managed to integrate considerations beyond the lowest price could help and inspire the Ministry of Social Affairs to include social considerations in its tenders. It could also help the Ministry of Finance to widen its scope and consider public spending not only in terms of value for money but also in terms of sustainability and impact. This cross-ministry group should be comprised of technical level officials from all relevant ministries.

\section{Stimulate the cooperation between mainstream businesses and social enterprises}

Cooperation between mainstream businesses and social enterprises remains significantly untapped in Estonia. Showcasing successful examples of mainstream businesses integrating social enterprises in their supply chains by purchasing their services and/or goods could be a source of inspiration. Raising awareness campaigns in media (e.g. social media, TV, radio) should highlight the social and/or environmental impact resulting from such a cooperation along with the benefits both mainstream businesses and social enterprises. Relevant networks, such as the Estonian Social Enterprise Network, could help to amplify the efforts of this endeavour. 


\section{Building capacity and developing social entrepreneurial skills}

Developing entrepreneurial skills, knowledge and attitudes can have significant benefits, including to boost entrepreneurship and ultimately to drive economic growth and job creation (European Commission, $2015_{[68]}$ ). It can also contribute to a wide range of positive outcomes, including personal development, employability, social and professional inclusion and active citizenship (European Commission, 2012[69]; Eurydice, 2012[70]).

In Estonia, entrepreneurship education is an essential component of the country's vision of an innovative society. It is also part of a broader objective to raise employment levels and create a more inclusive labour market, more particularly to include young people not in employment, education or training (NEETs) ${ }^{61}$ and to address the high youth unemployment rates. Since 2016 , all students in formal and vocational education tracks, across education levels, are required to take courses in entrepreneurship. Outside formal educational settings, there are opportunities for young people to develop core competencies for entrepreneurship through volunteering and youth projects. These activities provide a foundation upon which social entrepreneurship education can be developed and expanded.

In addition, there are a number of capacity building and business development programmes to support social entrepreneurs and non-profit organisations, including in order to improve their financial sustainability (Ministry of the Interior, 2014[21]). Even though these programmes are well established and of a high quality, there are gaps in the provision of support services in particular for social entrepreneurs and there is a clear need to improve skills for social impact measurement.

\section{Strengths}

\section{An encompassing policy framework for entrepreneurship education}

The Government provides policy support to entrepreneurship education via various strategic frameworks related to innovation, entrepreneurship, education and lifelong learning:

- The main focused strategy is the Entrepreneurship Education Development Plan "Be Enterprising!" signed at the Estonian Chamber of Commerce and Industry in 2010. This strategy is based on the work of the Entrepreneurship Education think-tank, which was set up by the Chamber of Commerce

\footnotetext{
${ }^{61}$ While youth unemployment and levels of NEETS are below the EU average, raising these two figures are set out as primary objectives in the Estonia 2020 competitiveness strategy. The strategy also sets out a further six objectives relating to education, employability and inclusion.
} 
and Industry to raise awareness about the importance of entrepreneurship education (Eurydice, 2012[70]).

- More recently, the Estonian Entrepreneurship Growth Strategy 2014-2020 (Ministry of Economic Affairs and Communications, $2013_{[71]}$ ), which provides a strategic framework for entrepreneurship and innovation policy, included a specific focus to "foster start-up entrepreneurship", particularly via learning materials and support services (e.g. advice, training, and access to networks), mainly provided by Startup Estonia ${ }^{62}$.

- In addition, the Estonian Lifelong Learning Strategy 2020 aims to promote "an approach towards learning that supports each learner's individual and social development, learning skills, creativity and entrepreneurship in the work of all levels and types of education." (Ministry of Education and Research, 2014[72])

- Finally, the Youth Field Development Plan 2014-2020 focuses largely on young people's employability by providing work opportunities but also by supporting young peoples' creativity, social inclusion and entrepreneurial spirit (Estonian Youth Work Centre/ Ministry of Education and Research, n.d.[73]).

As such, there is an encompassing policy framework for entrepreneurship education. The Ministry of Economic Affairs and Communications is currently drafting a new joint strategy for science, research and innovation with the Ministry of Education, and it is expected that entrepreneurship education will continue to play a key role in this strategic framework. These efforts are encouraging and represent a solid basis for policy support for social entrepreneurship education in the future.

\section{Growing opportunities for social entrepreneurship education in formal and non-formal settings}

Entrepreneurship education is offered in formal and non-formal educational settings. This framework offers an opportunity to introduce students to the concepts of social enterprise and social entrepreneurship. In 2011, the New National Curricula for Basic and Upper Secondary Schools recognised and defined entrepreneurship as a general competence for school students and set out goals, objectives and learning outcomes of entrepreneurship studies (Government of the Republic Regulation, 2011[74]). In 2016, the Ministry of Education and Research went a step further and launched a nation-wide programme for "the systematic development of entrepreneurial spirit and entrepreneurship education at all levels of education" (Edu \& Tegu)63, with the aim of supporting all students in primary, secondary, vocational and higher education to take part in activity-based entrepreneurship training. The programme is largely financed through the European Social Fund64 and delivered through a consortium of partners, including the Estonian Chamber of Commerce, the Estonian Employers' Confederation, the Estonian Service Industry Association, the Innove Foundation and Junior Achievement Estonia. As part of this programme, an entrepreneurial competence model has been developed, along with a wide range of modules for primary, secondary, vocational and higher education, as well as learning resources for students and teachers as part of their continuing professional development.65 The pre-incubation STARTER programme together with the Junior Achievement Estonian Student Companies programme, provide students with practical opportunities to develop their business ideas. The modules delivered at primary and secondary education include an overview of the concept of social entrepreneurship and recently, Junior Achievement published a new economics textbook, which includes a chapter on social entrepreneurship. In higher education, one

\footnotetext{
62 For more information, please see: https://www.startupestonia.ee/

${ }^{63}$ For more information, please see: http://ettevõtlusõpe.ee

64 Between 2016-2018, the total programme budget was EUR 6.01 million. With EUR 5.4 million from the European Social Fund and EUR 0.8 million from the Estonian Government.

${ }^{65}$ For more information, please see: https://xn--ettevtluspe-jfbe.ee/index.php
} 
of the ten modules on offer is devoted to social business. There is also a quality label, the "Enterprising School", which rewards excellence in entrepreneurship education. ${ }^{66}$

Outside formal educational settings, there are opportunities for young people to develop their entrepreneurial competencies. For example, the Estonian National Youth Council, in collaboration with the Youth Work Centre, manages a small-scale grant programme, the Youth Participation Fund ${ }^{67}$, which has an annual budget of EUR 330000 to which young people can apply to develop their innovative ideas. Another initiative is the Changemakers Academy ${ }^{68}$, a social entrepreneurship competition delivered by the Estonian Social Entrepreneurship Network (ESEN) and funded by the British Council. The competition, open to 14-19 year olds, provides an intensive 5-month learning-by-doing programme where teams of Estonian and Russian speaking young people work together to create marketing campaigns for social enterprises in their communities.

\section{A growing social entrepreneurship offer in higher education}

Entrepreneurship studies are now compulsory for all students in higher education. In addition, there are now a number of universities that provide courses on business administration and entrepreneurship with modules targeting specifically social entrepreneurship. These include Tallinn University, Tallinn University of Technology, the University of Tartu, the Estonian Business School and the Estonian Entrepreneurship University of Applied Sciences. Each of these universities offers modules on social entrepreneurship. In addition, the School of Governance, Law and Society at Tallinn University now offers a Master Degree in Social Entrepreneurship, which enables participating students the opportunity to develop their own ideas and projects. ${ }^{69}$

\section{Established providers of capacity building and business development support}

There is a relatively large ecosystem of individuals and organisations offering advisory services, many of which have developed considerable expertise in delivering support to specific types of organisations. For example, SMEs receive support from Enterprise Estonia, start-ups from Startup Estonia and non-profits from the National Foundation for Civil Society (NFCS). The Region Development Centres are unique in that they provide a set of support services and programmes to a wide range of organisations and individuals, including entrepreneurs, young entrepreneurs, start-ups, new and established SMEs, nonprofits and local governments.

\section{Table 2. Snapshot of providers of capacity building and business development support}

\begin{tabular}{|c|c|c|c|}
\hline Name & Mission & Budget & Additional comment \\
\hline $\begin{array}{l}\text { Enterprise } \\
\text { Estonia }\end{array}$ & $\begin{array}{l}\text { - Financial assistance, counselling and } \\
\text { training opportunities (business and } \\
\text { product development and design) } \\
\text { - Grants and services that could be of } \\
\text { relevance to social enterprises, most } \\
\text { notably around. }\end{array}$ & $\begin{array}{l}\text { EUR 600M } \\
\text { 2020) } \\
\text { As one of the agencies } \\
\text { implementing EU } \\
\text { structural funds. }\end{array}$ & $\begin{array}{l}\text { No data on how many of the } \\
\text { SMEs supported are social } \\
\text { enterprises or have a } \\
\text { social/environmental } \\
\text { objective. }\end{array}$ \\
\hline $\begin{array}{l}\text { Startup } \\
\text { Estonia }\end{array}$ & $\begin{array}{l}\text { - Training and business support for start- } \\
\text { ups } \\
\text { - Connects start-ups with potential investors }\end{array}$ & $\begin{array}{l}\text { EUR } 7 \mathrm{M} \text { funding from } \\
\text { the } \quad \text { European }\end{array}$ & $\begin{array}{l}\text { Nearly } 20 \% \text { of the } 550 \\
\text { companies, which }\end{array}$ \\
\hline
\end{tabular}

\footnotetext{
${ }^{66}$ For more information, please see: https://evkool.ee/en/enterprising-school-2/

67 The average grant size is 1000 Euros. For more information, please see: www.enl.ee/projekt/fond

68 For more information, please see: www.youth.changemakers.ee

${ }^{69}$ For more information, please see: $\underline{\text { https://www.tlu.ee/en/yti/social-entrepreneurship }}$
} 
- Works with regulators to remove barriers to setting up, operating or investing in a startup

- Areas of focus: new technologies.
Regional received support from

Development Fund. Start-Up Estonia, have a societal or environmental objective.

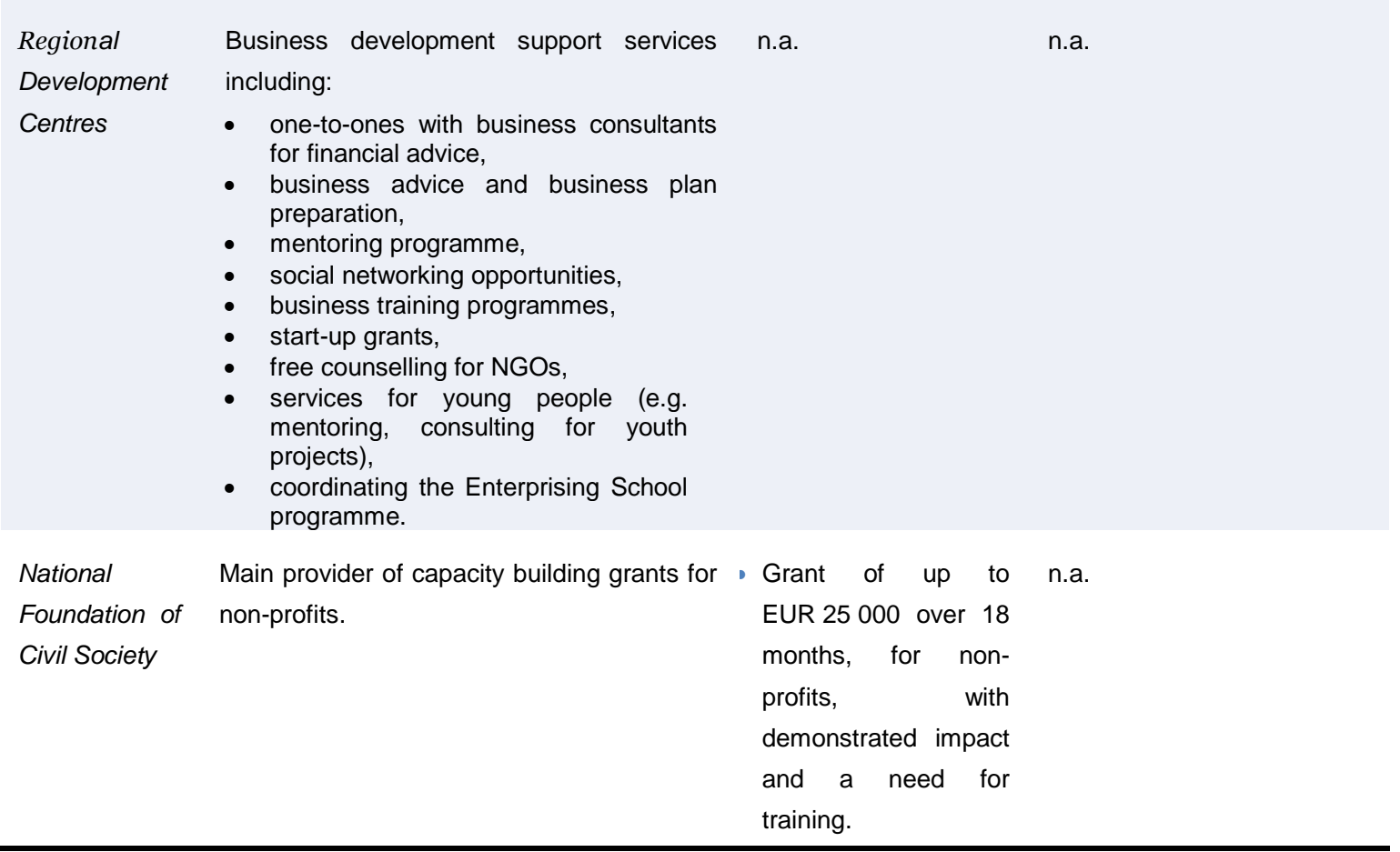

Source: OECD elaboration based on the OECD study visit (2019) and the following websites: https://www.eas.ee, https://startupestonia.ee/ and https://www.kysk.ee/about-us

In addition to these public schemes, social enterprises can also receive support from Estonia's venture philanthropy fund, the Good Deed Foundation (GDF). ${ }^{70}$ The GDF provides business development and capacity building support to a number of social enterprises. In addition, the GDF and NFCS have been running for four years now a social enterprise incubator, NULA. ${ }^{71}$ Among the five finalists to the NULA competition, up to three receive financial support worth EUR 25,000 from the NFCS. The programme itself consists of five one-day training sessions with experts to develop participants' ideas. In addition, the country's largest business competition, Brain Hunt ${ }^{72}$, created a separate category for social enterprises, in collaboration with NFCS, ESEN and SEB Bank. Finalists take part in the accelerator programme (i.e. mentoring and training on product development, export strategies, pitching and business model innovation).

\section{Challenges}

\section{A workforce insufficiently skilled and a lack of business skills for social entrepreneurs}

The lack of a skilled workforce has been identified as one of the main barriers to long-term investment in the country (OECD, 2017 $[5]$ ). Roughly, $30 \%$ of adults do not have professional qualifications and, in 2014 , approximately $40 \%$ of employees stated that their skills were lower than the level required for their job at

\footnotetext{
70 For more information, please see: https://www.heategu.ee/en

${ }^{71}$ For more information, please see: $\mathrm{https}: / /$ nula.kysk.ee/et

72 For more information, please see: $\underline{\text { http://www.ajujaht.ee/ }}$
} 
the time of hiring. This was the highest percentage across the EU28 at the time (OECD, 2017 $\left.7_{[5]}\right)$. There are particular concerns around the lack of skills relating to problem solving skills in technology-rich environments. Nearly one third of the adult population is unable or unwilling to use a computer to solve a problem (European Commission, 2014[75]). In addition, there are shortages in terms of problem-solving and socio-emotional skills, including collaboration and communication skills (European Commission, 2014[75]). Although the country has made improvements in PISA scores (OECD, 2016 [76]; OECD, 2017[77]), efforts to build entrepreneurial and socio-emotional skills via the systematic entrepreneurship education programme, should continue.

There is a lack of detailed research about the specific skills shortages facing social entrepreneurs and social enterprises in Estonia. Key stakeholders interviewed during the OECD's study visit, identified nonetheless a number of critical gaps around measuring impact, contract readiness as well as traditional business skills (e.g. leadership, project management, marketing and financial management).

\section{A lack of skills around social impact measurement}

Stakeholders met during the OECD's study visit highlighted the need to improve social impact measurement capacities in Estonia. Some attempts to address this situation exist. For example, ESEN has created a handbook on methods for impact measurement and a website ${ }^{73}$ for its members to share and report on their social impact. Universities, such as Tartu, Tallinn and Taltech, have also established links with non-profit associations to help them measure their social impact. ${ }^{74}$ Despite these initiatives, awareness of the importance of social impact measurement is low. Social enterprises and non-profit associations more generally do not systematically measure their social impact, which might be due to the lack of tools and methods to measure social impact measurement, and specific funding programmes to help social enterprises and non-profit associations in that endeavour do not exist. ${ }^{75}$ In a recent survey, social enterprises reported needing support to measure their social impact (Kiisel et al., 2017[78]).

\section{Legal forms acting as a barrier to accessing advisory and support services}

Some social enterprises may be unable to access a wider range of support services because of their legal form. For example, even though the RDCs provide services to both companies and non-profit associations, these services are provided separately. Social enterprises in the form of a non-profit association cannot apply for start-up grants or access the business support available to limited companies. At the same time, social enterprises in the form of a limited company, are not able to receive support from the RDCs' nonprofit specialists and the support they can receive from private enterprise specialists is not always targeted to their business model which prioritise social objectives. Similarly, social enterprises, which are limited companies, cannot apply for capacity building grants from the NFCS, and social enterprises that are nonprofit associations are prohibited from accessing the wide range of advisory and support services available to limited companies from Enterprise Estonia and Startup Estonia.

This is a missed opportunity since these organisations have considerable expertise in providing support services to their relevant constituencies. In other words, social enterprises that are non-profit associations are unable to access business development services that may help them strengthen their sustainability and growth. Private limited companies on the other hand do not have access to support services that could help them develop and strengthen their social impact, understand the needs of their beneficiaries and/or work with public sector commissioners.

\footnotetext{
${ }^{73}$ For more information, please see: https://www.maailmamuutjad.ee/

${ }^{74}$ OECD Study Visit, April 2019.

$75 \mathrm{lbid}$.
} 


\section{Policy issues}

\section{An ecosystem approach for developing skills and building capacity for social enterprises}

Developing a consistent approach to capacity development for social entrepreneurs requires taking into account their different trajectories and needs. For example, a social enterprise created by an individual entrepreneur will not have the same needs as a social enterprise resulting from an organisational transformation (e.g. non-profit organisation into a social enterprise). In addition, in Estonia, many social entrepreneurs develop their social projects in parallel to their work, which is not necessarily the case of other countries where social enterprises are first incubated within a civil society or social economy organisation or a public organisation. This situation has important implications on capacity building because this type of social entrepreneur, which may have a strong knowledge of their field of action, lacks experience and knowledge about how to manage impact (Luke Georghiou, 2018[79]).

When considering how to develop the skills and capacities of social entrepreneurs, it is essential to examine what different players can offer, beyond the formal education system, including:

- Networks which provide opportunities for intra-sectoral and cross-sectoral co-operation collaboration and co-ordination, mutual support, learning, knowledge transfer, brokering relationships, raising awareness, developing and sharing common resources (TEPSIE, 2016[80]).

- Social labs which are "a safe space for experimentation, allow to take distance from an organisation's daily routines and responsibilities, which aim to develop novel approaches to addressing social issues and can demonstrate impact (Sigaloff, $\left.2019_{[81]}\right) "$. These labs employ a variety of methods, such as ethnography, action research, data methods and public participation, bring together a wide range of stakeholders and test ideas in practice through the development of prototypes.

- Incubators support the development of early stage ideas or early stage companies through the provision of business advice and support, office space and access to networks. This support can be provided over months or years. Incubators are important drivers of local and regional economic development.

- Accelerators also support early stage companies but they differ from incubators in that they are fixed-term, cohort-based, mentorship-driven, have a competitive application process and culminate in a "demo" day that connects participants with potential investors (Cohen and Hochberg, 2014[82]). They provide an intense, rapid, immersive experience, which combines training, mentoring, learning by doing, peer support and in some cases financing (Miller and Bound, 2011[83]).

- Advisory services for social entrepreneurs can be provided by individuals or organisations and usually include advice, training, mentoring and/or coaching on subjects ranging from business planning, financial management, operations and human resources, sales and marketing, contract readiness and impact measurement.

There is growing evidence that such approaches are successful. For example, start-ups that receive support from incubators and accelerators are more likely to survive, grow and secure external finance (Madaleno et al., 2018[84]). They also deliver positive spillover effects in terms of regional and local development (Madaleno et al., 2018[84]). Research also suggests that accelerators have a positive impact on local entrepreneurial ecosystems in terms of the financing environment. Areas in which accelerators are established attract more seed and early stage investment, which appears to spill-over to nonaccelerated firms as well (Fehder et al., 2014[85]).

In Estonia, there is a wide range of individuals and organisations providing business support and advisory services, which social entrepreneurs and social enterprises are able to access. There are innovation labs inside and outside of the Government, the Innovation Lab and Accelerate Estonia, which bring together 
various stakeholders and provide a space for experimentation within the public sector. These are promising foundations upon which to build.

There are a number of elements, however, which are missing or need to be reinforced and could be of particular benefit in the Estonian context. For example, apart from NULA, there are no cohort-based, fixedterm incubation or accelerator programmes specifically designed for social entrepreneurs or non-profit leaders. Such programmes could be introduced to help develop the skills and capacities of social entrepreneurs, improve the financial sustainability of non-profit organisations, provide value for money by providing training to a cohort rather than individuals and facilitate the creation of new social networks. Examples of these kinds of programmes from the UK include Bethnal Green Ventures ${ }^{76}$, The Young Foundation's Young Academy (Teasdale and Sargsyan, 2017[86])(see Box 7) and UnLtd's Thrive Accelerator ${ }^{77}$.

\section{Box 7. The Young Academy}

The Young Foundation established its incubation programme, the Young Academy, in 2014. The Young Academy aims to build the business capacity of early-stage education ventures and increase those ventures' access to growth capital in order to improve educational outcomes for disadvantaged young people. The programme consists of an intensive group-based incubator programme of 12 one-day workshops and one-to-one support from specialist advisors and coaches culminating in a demo day when ventures pitch to a group of potential funders, investors and customers.

The key elements of the programme include: a cohort based approach which enables peer-to-peer support and learning, laying the foundations for future collaborations and partnerships; action-learning workshops based on the Social Business Model Canvas, a social business analysis and planning tool; tailored support on social impact measurement from New Philanthropy Capital to help ventures measure and report their impact; and an accelerator model which means that support is targeted at the stages between proof of concept and proof of market, where ventures decide either to pivot or persevere with their plans in order to grow quickly and achieve impact.

To date, the programme has supported 52 ventures working to reduce educational inequality. As a result of their participation, these ventures have increased their turnover by $240 \%$; accessed GBP $4.5 \mathrm{~m}$ of social finance, including GBP 500,000 from the Young Foundation's own investment fund; scaled-up to reach 160,000 young people and teachers. The Young Academy was funded by the Office for Civil Society's Social Incubator Fund, Bank of America Merrill Lynch, UBS and Esmée Fairbairn Foundation.

Source: James Teasdale, Tatevik Sargsyan, 2017, The Young Academy Impact Report, London, The Young Foundation. Available at: https://youngfoundation.org/publications/young-academy-impact-report/

The main network for social enterprises, ESEN, has played an important role in terms of raising awareness of the role and benefits of social enterprises. However, there are still considerable gaps in terms of networking in the country. Networks are needed, especially those that can promote cross-sectoral collaboration, co-ordination and co-operation in the fields of social innovation and social entrepreneurship. Such networks could play a convening role, acting as a "bridge" between universities, the public and private

\footnotetext{
${ }^{76}$ For more information, please see: https://bethnalgreenventures.com/

77 For more information, please see: $\underline{\text { https://www.unltd.org.uk/our-support/scaling-up/thrive }}$
} 
sectors and civil society. As mentioned in Sections 4 and 5, there is a particular role for intermediaries that can integrate networking opportunities, financial support and advisory services.

\section{Recognising the importance of social impact measurement}

Social impact measurement is critical for social enterprises. It enables them to provide data for performance management and evidence of their impact, which can raise awareness of the benefits they generate and attract further investments. The importance of social impact measurement has come to the fore over the last decade. For example, guidelines have been published by the European Commission, developed by GECES, to allow social enterprises to better measure and demonstrate their social impact, and so help them in their discussions with funders, investors and commissioners. Similarly, work has been undertaken by the OECD (OECD, 2015[87]) and the Working Group on Impact Measurement, set up by the taskforce on social impact investment established by the G8. ${ }^{78}$

There are numerous approaches, methods and tools for social impact measurement. Organisations such as IRIS+ and the Global Impact Investing Network (GIIN), and Global Value Exchange provide databases of metrics, indicators and tools for measuring social impact. Irrespective of the tools used, there are five main stages to managing, measuring and reporting on social impact: setting objectives; analysing stakeholders; measuring results; verifying and valuing impact; monitoring and reporting (Hehenberger, Lisa; Harling, Anna-Marie; Scholten, 2015[88]).

One of the key issues in determining which approaches and tools to use is the stage of development of the social enterprise. For example, requiring a start-up or recently created social enterprise to produce a randomised control trial $(\mathrm{RCT})$ evaluation of their impact would be inappropriate since the social enterprise would not have the track record or the financial resources to carry out such an evaluation. Nesta, the UK's innovation charity has developed Standards of Evidence in order to help innovative organisations determine which types of evidence are proportionate and relevant to their stage of development (see Table 3). Such an approach balances the need for evidence without hampering innovation efforts.

\section{Table 3. Nesta's Standards of Evidence}

\begin{tabular}{c|l|l}
\hline LEVEL & \multicolumn{1}{c|}{ EXPECTATION } & \multicolumn{1}{c}{ HOW THE EVIDENCE CAN BE GENERATED } \\
\hline $\mathbf{1}$ & $\begin{array}{l}\text { You can give an account of impact. By this we mean } \\
\text { providing a logical reason, or set of reasons, for why } \\
\text { your intervention could have an impact and why that } \\
\text { would be an improvement on the current situation. }\end{array}$ & $\begin{array}{l}\text { You should be able to do this yourself, and draw } \\
\text { upon existing data and research from other sources. }\end{array}$ \\
\hline $\mathbf{2}$ & $\begin{array}{l}\text { You are gathering data that shows some change } \\
\text { amongst those receiving or using your intervention. }\end{array}$ & $\begin{array}{l}\text { At this stage, data can begin to show effect but it will } \\
\text { not evidence direct causality. You could consider } \\
\text { such methods as: pre and post- survey evaluation; } \\
\text { cohort/panel study, regular interval surveying. }\end{array}$ \\
\hline $\mathbf{3}$ & $\begin{array}{l}\text { You can demonstrate that your intervention is is } \\
\text { causing the impact, by showing less impact amongst } \\
\text { those who don't receive the product/service. }\end{array}$ & $\begin{array}{l}\text { We will consider robust methods using a control (or } \\
\text { another well-justified method) that begin to isolate } \\
\text { the impact of the product/service. Random selection } \\
\text { of participants strengthens your evidence at this } \\
\text { Level, you need to have a sufficiently large sample } \\
\text { at hand (scale is important in this case). }\end{array}$ \\
\hline $\begin{array}{l}\text { You are able to explain why and how your } \\
\text { intervention is having the impact you have observed } \\
\text { and evidenced so far. An independent evaluation } \\
\text { validates the impact. In addition, the intervention can } \\
\text { deliver impact at a reasonable cost, suggesting that } \\
\text { it could be replicated and purchased in multiple } \\
\text { locations. }\end{array}$ & $\begin{array}{l}\text { At this stage, we are looking for a robust } \\
\text { independent evaluation that investigates and } \\
\text { validates the nature of the impact. This might include } \\
\text { endorsement via commercial standards, industry } \\
\text { Kitemarks etc. You will need documented } \\
\text { standardisation of delivery and processes. You will } \\
\text { need data on costs of production and acceptable }\end{array}$ \\
\hline
\end{tabular}

${ }^{78}$ For more information see: https://www.thinknpc.org/resource-hub/impact-measurement-working-groupmeasuring-impact/ 


\begin{tabular}{c|l|l}
\hline $\mathbf{5}$ & $\begin{array}{l}\text { You can show that your intervention could be } \\
\text { operated up by someone else, somewhere else and } \\
\text { scaled up whilst continuing to have positive and } \\
\text { direct impact on the outcome, and whilst remaining } \\
\text { a financially viable proposition. }\end{array}$ & $\begin{array}{l}\text { We expect to see use of methods like multiple } \\
\text { replication evaluations; future scenario analysis } \\
\text { fidelity evaluation. }\end{array}$ \\
\hline
\end{tabular}

Source: Joe Ludlow and Ruth Puttick(2013) Standards of Evidence: An approach that balances the need for evidence with innovation. Available at: https://media.nesta.org.uk/documents/standards_of_evidence.pdf

Proportionality (i.e. measuring should not be more costly than generating social impact) should be considered by funders, partners and commissioners when asking for evidence of social impact. Similarly, social enterprises should examine what tools and methods of impact measurement are most apporiate to their stage of development.

\section{Recommendations}

\section{Embed an explicit social entrepreneurship component in entrepreneurship education programmes}

Rather than developing social entrepreneurship education alongside entrepreneurship education, it may be useful to consider mainstreaming social entrepreneurship in entrepreneurship education. Doing so would deliver a range of benefits such as increasing employability, raising student understanding of social and environmental issues, and fostering social innovation. Potential elements to consider might include: measuring social and environmental impact; social enterprise business models; understanding social and environmental issues and challenges; and co-designing solutions to social challenges with beneficiaries. This may also require broadening the scope of university incubator STARTER to include social and environmental ideas and expanding programmes such as Changemakers Academy.

\section{Conduct mapping of the skills needs of social entrepreneurs}

There is currently no data on the specific demand for and supply of skills for social enterprises. Such research should consider the needs of social enterprises, which are in the form of non-profit associations and private limited companies. In 2015, the Ministry of Education and Research launched a new initiative, OSKA, to monitor and forecast labour market needs. ${ }^{79}$ OSKA examines the skills needs of specific sectors (such as ICT, social work, forestry and accounting) and provides guidance to various stakeholders in government, education and business. The information in these reviews is used to shape curriculum developments, strategic planning at all levels of education (including VET) as well as advisory services for business (European Commission, 2014 ${ }_{[75]}$ ). It is therefore essential to leverage existing tools, such as OSKA, to identify the skills needs of social entrepreneurs and social enterprises.

\section{Extend and diversify the capacity building offer for social entrepreneurs}

The majority of capacity building services currently available are tailored to an individual or organisations' specific needs, which is highly valuable and should continue. At the same time, the Government as well as the main providers of capacity building and business development support programmes might consider alternative approaches, especially those which are cohort based, fixed-term, involve elements of peer learning, and connect social entrepreneurs to potential investors or buyers. Estonia could benefit from setting up accelerators and workshops or short courses on topics relating specifically to social enterprises such as: setting up a social enterprise; scaling, dissemination and replication; transforming a non-profit

${ }^{79}$ For more information, please see: https://oska.kutsekoda.ee/ 
into a social enterprise; and measuring social impact. These additional types of support could be funded by the NFCS and delivered by RDCs or a new intermediary (described below) with funding from ESF+.

\section{Ensure an equal access of social enterprises to mainstream business development programmes}

In addition to diversifying the type of capacity building and skills development programmes on offer, it is important to ensure that social enterprises are not prohibited from accessing capacity building or business development support because of their legal form. As mentioned in Section 3, one option may be to open the List of Public Benefit Organisations to social enterprises in the form of a private limited company. Thereafter any organisation on the List of Public Benefit Organisations would be able to apply to the NFCS for capacity building support. Similarly, RDCs should consider opening up their support services for startups and established companies to social enterprises in the form of non-profit associations.

\section{Facilitate access to funding opportunities for social enterprises}

As mentioned in Section 4, a new intermediary, if established, could provide financial support as well as networking opportunities and capacity building programmes (such as incubator and accelerator programmes). Such an intermediary would also provide tools, advice and support with social impact measurement. Such an approach could help build the social enterprise ecosystem by developing the capacity and resources available for social enterprise development. It would also better link capacity building programmes to the provision of finance and funding opportunities for social enterprises.

This intermediary could be an independent non-profit association, working closely with the Ministry of the Interior, the NFCS, RDCs and other key organisations in the field such as ESEN and GDF. The intermediary could be funded through the European Commission's Employment and Social Innovation (EaSI) Capacity Building Investments Window, which provides seed funding for the establishment of new intermediaries. Alternatively, the Government could consider setting up such an intermediary at the regional level, as a "Baltic Social Enterprise Development Fund". If so, funding could be secured through the European Fund for Strategic Investments (EFSI), which supports investment in strategic projects across Europe in areas such as education, innovation and support for small and mid-sized businesses. ${ }^{80}$

\footnotetext{
${ }^{80}$ For more information, please see: https://www.eib.org/en/efsi/what-is-efsi/index.htm\#
} 


\section{References}

Ballantyne, P. (2014), Challenge prizes: a practice guide, Centre for Challenge Prizes, Nesta, London.

BEPA (2015), Empowering people, driving change, https://ec.europa.eu/docsroom/documents/13402/attachments/1/translations.

Browne, J. et al. (2018), "Faces of Joblessness in Estonia: A People-centred perspective on employment barriers", OECD Social, Employment and Migration Working Papers, Vol. 206, https://doi.org/10.1787/6d9cd656-en.

Burstein, M. and F. Murray (2016), "Innovation prizes in practice and theory", Harvard Journal of Law \& Technology, Vol. Volume 29, Number 2 Spring 2016.

Cohen, S. and Y. Hochberg (2014), "Accelerating Startups: The Seed Accelerator Phenomenon", SSRN Electronic Journal.

Defourny, J. (2008), "Social Enterprise in Europe: Recent Trends and Developments", EMES Working Papers, No. 08/01.

Deloitte (2017), The 2017 Deloitte Millennial Survey. Apprehensive Millennials: Seeking Stability and Opportunities in an Uncertain World., https://www2.deloitte.com/content/dam/Deloitte/global/Documents/About-Deloitte/gx-deloittemillennial-survey-2017-executive-summary.pdf.

ESCC/CIRIEC (2017), Recent evolutions of the Social Economy in the European Union, "Visits and Publications" Unit of the European Economic and Social Committee, European Union, Brussels.

ESEN (2019), Estonian Social Enterprise Network, https://sev.ee/en/who-are-we/.

Estonian Youth Work Centre/ Ministry of Education and Research (n.d.), Youth Field Development Plan 2014-2020.

ESTVCA (2018), ESTVCA 2018 Report. Estonian Private Equity and Venture Capital Association, http://media.voog.com/0000/0035/9563/files/EstVCA\%202018\%20report.pdf.

European Commission (2019), Country Report Estonia 2019.

European Commission (2019), Country Report Estonia 2019, https://ec.europa.eu/info/sites/info/files/file import/2019-european-semester-country-reportestonia en.pdf. 
European Commission (2019), Social enterprises and their ecosystems in Europe. Updated country report: Estonia. Author: Katri-Liis Reimann. Luxembourg: Publications Office of the European Union., https://europa.eu/!Qq64ny.

European Commission (2018), Digital Economy and Society index 2018, Country Report Estonia.

European Commission (2018), EaSI: Better access to finance for a more social Europe, EU Publications Office/European Investment Fund.

European Commission (2015), Entrepreneurship Education: A road to success, https://ec.europa.eu/growth/content/entrepreneurship-education-road-success-0 en.

European Commission (2014), EU Skills Panorama 2015: Estonia Analytical Highlight, http://skillspanorama.cedefop.europa.eu/sites/default/files/EUSP AH Estonia 0.pdf.

European Commission (2013), How Companies Influence Our Society: Citizens' View, http://www.csr.ee/wp-content/uploads/2016/03/Ettevotete-uhiskondliku-moju-javastutustundliku-tegutsemise-uuring Euroopa-Komisjon.pdf.

European Commission (2012), Rethinking Education: Investing in skills for better socioeconomic outcomes.

European Commission (2011), Social Business Initiative Creating a Favourable Climate for Social Enterprises, Key Stakeholders in Social Economy and Innovation, Luxembourg: Publications Office of the European Union.

European Union (2019), 2019 European Semester: Assessment of progress on structural reforms, prevention and correction of macroeconomic imbalances, and results of in-depth reviews under Regulation (EU) No 1176/2011.

European Union (2017), "A Macroeconomic Perspective on non-performing loans (NPLs)", $A$ Quarterly Report on the Euro Area (QREA), Vol. 16/1, https://ec.europa.eu/info/sites/info/files/ip049 en 1 npls.pdf.

European Venture Philanthropy Association (2018), A Practical Guide to Venture Philanthropy and Social Impact Investment, https://evpa.eu.com/knowledge-centre/publications/venturephilanthropy-and-social-impact-investment-a-practical-gu.

Eurydice (2012), Entrepreneurship Education at School in Europe, Luxembourg: Publications Office of the European Union, https://eacea.ec.europa.eu/nationalpolicies/eurydice/content/entrepreneurship-education-school-europe en.

Fehder et al. (2014), Accelerators and the regional supply of venture capital investment, Seed Accelerator Rankings Project, http://www.seedrankings.com/pdf/accelerators-and-regionalsuppy-of-vc-investment.pdf.

Freedom House (2018), Nations in Transit 2018 : Estonia country profile, https://freedomhouse.org/report/nations-transit/2018/estonia.

Gök, A. (2013), "The Impact of Innovation Inducement Prizes", Nesta Working Paper, Vol. 13/18. 
Government (2017), Taskforce recommends including more companies in solving problems, https://www.riigikantselei.ee/en/news/task-force-recommends-including-more-companiessolving-societal-problems.

Government of the Republic Regulation (2011), National curriculum for upper secondary schools.

Hehenberger, Lisa; Harling, Anna-Marie; Scholten, P. (2015), A practical guide to measuring and managing impact, European Venture Philanthropy Association (EVPA).

Jeppesen, L. and K. Lakhani (2010), "Marginality and Problem-Solving Effectiveness in Broadcast Search", Organization Science, Vol. 21.

Kalil, T. (2006), Prizes for Technological Innovation, The Hamilton Project, The Brookings Institution, Washington DC.

Kay, L. (2011), "The effect of inducement prizes on innovation: Evidence from the Ansari X Prize and the Northrop Grumman Lunar Lander Challenge", $R$ and $D$ Management, Vol. 41(4).

Kiisel et al. (2017), Analysis of the support system for social entrepreneurship, RAKE: Centre for Applied Research in Social Sciences, University of Tartu.

Kulbok-Lattik, E. (2015), "The Historical Formation and Development of Estonian Cultural Policy Tracing the Development of Estonian Community Houses (Rahvamaja).”, Jyväskylä studies in education, psychology and social research, Vol. 537.

Let's Do It Foundation (2019), https://www.letsdoitworld.org/.

Luke Georghiou (2018), A European Ecosystem for Social Innovation, European Commission.

Madaleno et al. (2018), "Incubators, Accelerators and Regional Economic Development", Discussion Paper Series, IZA DP, No. 11856, http://ftp.iza.org/dp11856.pdf.

Mair, J. and I. Martí (2006), "Social entrepreneurship research: A source of explanation, prediction, and delight", Journal of World Business, Vol. 41/1, pp. 36-44, https://doi.org/10.1016/j.jwb.2005.09.002.

McKinsey \& Company (2009), "And the Winner Is...", Philanthropists and Governments Make Prizes Count.

Miller, P. and K. Bound (2011), Start Up Factories.

Ministry of Economic Affairs and Communications (2013), Estonian Entrepreneurship Growth Strategy 2014-2020.

Ministry of Education and Research (2014), Estonian Lifelong Learning Strategy 2020.

Ministry of Finance (2019), , https://www.rahandusministeerium.ee/en/public-procurement-policy (accessed on 7 May 2019).

Ministry of the Interior (2014), Estonian Civil Society Development Plan 2015-2020.

Murray, F. et al. (2012), "Grand Innovation Prizes: A theoretical, normative, and empirical evaluation”, Research Policy, Vol. 41(10): 1779-1792. 
National Audit Office of Estonia (2017), State's activity upon preparing for the Work Ability reform, https://www.riigikontroll.ee/tabid/206/Audit/2422/language/en-US/Default.aspx.

Nicholls, A. (2006), Social Entrepreneurship. New Models of Sustainable Social Change, Oxford University Press.

Nicholls, A. and B. Huybrechts (2012), "Social Entrepreneurship: Definitions, Drivers, and Challenges", https://link.springer.com/chapter/10.1007/978-3-8349-7093-0 2.

Nordic Council (2018), Discussion paper on social impact investment in the Nordic Baltic Region. Ideas and opportunities needs and challenges, https://sua.Iv/wpcontent/uploads/2018/09/SocialimpactinvestmentintheNordic-Balticregion A4 5bl trykk.pdf.

OECD (2019), "Boosting Social Entrepreneurship and Social Enterprise Development in the Netherlands, In-depth Policy Review", OECD Publishing, Paris.

OECD (2019), Financing SMEs and Entrepreneurs 2019: An OECD Scoreboard. Full Country Profile. Estonia., https://read.oecd-ilibrary.org/industry-and-services/financing-smes-andentrepreneurs-2019 b347f576-en\#page2.

OECD (2019), Financing SMEs and Entrepreneurs 2019: An OECD Scoreboard. Full Country Profile: Estonia, https://read.oecd-ilibrary.org/industry-and-services/financing-smes-andentrepreneurs-2019 b347f576-en\#page2.

OECD (2018), OECD Regions and Cities at a Glance 2018, OECD Publishing, https://doi.org/10.1787/reg cit glance-2018-en.

OECD (2018), "Regional well-being in OECD countries: Estonia", OECD Regional Well-Being Database, https://www.oecdregionalwellbeing.org.

OECD (2017), OECD Economic Surveys: Estonia 2017, OECD Publishing, Paris, https://dx.doi.org/10.1787/eco surveys-est-2017-en.

OECD (2017), PISA 2015 Results (Volume V): Collaborative Problem Solving, PISA, OECD Publishing, Paris, https://dx.doi.org/10.1787/9789264285521-en.

OECD (2016), PISA 2015 Results (Volume I): Excellence and Equity in Education, PISA, OECD Publishing, Paris, https://dx.doi.org/10.1787/9789264266490-en.

OECD (2015), Social Entrepreneurship: Social Impact Measurement for Social Enterprises, https://www.oecd.org/social/PB-SIM-Web FINAL.pdf.

OECD (2015), "Social Impact Investment: Building the evidence base", https://www.oecd.org/publications/social-impact-investment-9789264233430-en.htm.

OECD (2014), e-Estonia takes digital government innovation to next level, https://www.oecd.org/governance/observatory-public-sector-innovation/blog/page/eestoniatakesdigitalgovernmentinnovationtonextlevel.htm\#.

OECD (2014), OECD Data Working Age Population.

OECD (2010), "Social Entrepreneurship and Social Innovation", in SMEs, Entrepreneurship and Innovation, OECD Publishing, Paris, https://dx.doi.org/10.1787/9789264080355-50-en. 
OECD (1999), Social Enterprises, OECD Publishing, Paris,

https://dx.doi.org/10.1787/9789264182332-en.

OECD (n.d.), Financing SMEs and Entrepreneurs 2019: An OECD Scoreboard. Full Country Profile: Estonia, https://read.oecd-ilibrary.org/industry-and-services/financing-smes-andentrepreneurs-2019 b347f576-en\#page2.

OECD/EC (2018), Better Entrepreneurship Policy: Guidance Note "Institutional Frameworks", https://www.betterentrepreneurship.eu/en/node/53.

OECD LEED (2000), OECD LEED Forum on Social Innovations, https://www.oecd.org/fr/cfe/leed/forum-social-innovations.htm.

OECD/EC (2018), Better Entrepreneurship Policy Tool: Guidance Note on Access to Finance, https://www.betterentrepreneurship.eu/en/node/51.

OECD/EC (2017), Boosting Social Enterprise Development: Good Practice Compendium, OECD Publishing, https://doi.org/10.1787/9789264268500-en.

OECD/UCLG (2019), Report on World Observatory on Subnational Government.

Põder, A. (2017), "The Socio-Economic Determinants of Entrepreneurship in Estonian Rural Municipalities", Doctoral Theses of the Estonian University of Life Sciences.

Public Procurement Register (2018), , https://riigihanked.riik.ee/rhr-web/\#/ (accessed on 7 May 2019).

Raudsaar, M. (2016), "Developments of social entrepreneurship in Estonia”, Institute of Social Studies, Univeristy of Tartu.

Saltuk et al. (2014), Spotlight on the Market: The Impact Investor Survey, Global Impact Investing Network, https://thegiin.org/research/publication/spotlight-on-the-market-the-impactinvestor-survey.

Santos F., Salvado J.C., de Carvalho I.L., S. (2013), "The Life Cycle of Social Innovations. In: Osburg T., Schmidpeter R. (eds) Social Innovation. CSR”, Sustainability, Ethics \& Governance.

SEFORIIS (2017), European Policy Brief. Measuring social innovation in the community innovation survey: Experience and evidence from the CIS2015 conducted in Flanders, https://static1.squarespace.com/static/56d2eebbb654f9329ddbd20e/t/59a5229d8dd041cc6f7 2babf/1503994532990/Deliverable+6.3+policy+brief+KUL.pdf.

Sigaloff, C. (2019), Social Labs: Beyond experimentation, towards a new model for public participation, Make a Difference Institute, Hong Kong.

SSE Knowledge Hub for the SDGs (2018), "From the economic to the social value contribution of the Social Economy, Methodological approach of assessment of the social value created, with an application to Spain", Draft paper prepared in response to the UNTFSSE Call for Papers 2018.

Starr, K. (2013), "Dump the Prizes", Stanford Social Innovation Review,.

Startup Estonia (2019), https://www.startupestonia.ee/startups, https://www.startupestonia.ee/startups. 
Tallinn University (2019), "„Kodanikuühiskonna arengukava mõjude hindamine“”, Report: draft.

Tallinn University, IBS, Turu-Uuringute AS. Tarbijate ühistud., https://maksikook.coop.ee/tarbijate-uhistud/.

Tana Ziegler et al. (2017), Shifting paradigms: the 4th European Alternative Finance Benchmarking Report, Cambridge Centre for Alternative Finance, https://www.jbs.cam.ac.uk/fileadmin/user upload/research/centres/alternativefinance/downloads/2019-04-4th-european-alternative-finance-benchmarking-industry-reportshifting-paradigms.pdf.

Teasdale, J. and T. Sargsyan (2017), The Young Academy Impact Report, The Young Foundation, London, https://youngfoundation.org/publications/young-academy-impact-report/.

TEPSIE (2016), Building the Social Innovation Ecosystem. A deliverable of the project: "The theoretical, empirical and policy foundations for building social innovation in Europe", European Commission, Brussels.

The Nielsen Company (2013), The Nielsen Global Survey on Corporate Social Responsibility: Consumers who care and they will reward companies with their wallets., http://www.csr.ee/wp-content/uploads/2016/03/Nielsen-Global-Report-Consumers-Who-CareAugust-2013.pdf.

Thompson, J. (2008), "Social enterprise and social entrepreneurship: where have we reached?: A summary of issues and discussion points", Social Enterprise Journal, Vol. 4/2, pp. 149-161, http://dx.doi.org/10.1108/17508610810902039.

Trumm, A. (2006), "Recent developments of Estonia's social protection system", Background Paper Prepared for the EU8 Social Inclusion Study. Document of the World Bank, Vol. 52, http://siteresources.worldbank.org/INTECONEVAL/Resources/EstoniaSocialPolicyReview.pdf.

Tuukka Toivonen, E. (2018), "Sparking social innovation through challenge prizes, Evidence on Teams, Ideas and Incubation from Finland,", Sitra studies 133.

UN (2017), "Our World in Data: Age dependency ratio projected to 2100, Estonia”, UN Population Division (2017 Revision), UNDESA, https://esa.un.org/unpd/wpp/Download/Standard/Population/.

Union, E. (n.d.), A Quarterly Report on the Euro Area (QREA), vol. 16, no1, https://ec.europa.eu/info/sites/info/files/ip049 en 1 npls.pdf.

Varga, E. and M. Hayday (2017), A recipe book for social finance, RAND Europe/Ecorys, Brussels, https://op.europa.eu/en/publication-detail/-/publication/f1b8099b-fd4c-11e5-b71301aa75ed71a1/language-en.

Winborg and Landström (2000), "Financial bootstrapping in small businesses: Examining small business managers' resource acquisition behaviors", Journal of Business Venturing. 


\section{Annex 1.A. Key features, opportunities and challenges of social enterprises under different legal forms in Estonia}

\begin{tabular}{|c|c|c|c|c|c|c|}
\hline & $\begin{array}{c}\text { Social } \\
\text { Enterprise }\end{array}$ & $\begin{array}{c}\text { Non Profit } \\
\text { Association }\end{array}$ & $\begin{array}{l}\text { Commercial } \\
\text { Association }\end{array}$ & Foundation & $\begin{array}{l}\text { Limited Liability } \\
\text { Company }\end{array}$ & $\begin{array}{c}\text { Hybrid form } \\
\text { Association and } \\
\text { LLC }\end{array}$ \\
\hline $\begin{array}{l}\text { Economic } \\
\text { activity }\end{array}$ & $\begin{array}{l}\text { Continuous } \\
\text { economic activity }\end{array}$ & $\begin{array}{l}\text { No limitation, } \\
\text { unless it is the } \\
\text { primary purpose }\end{array}$ & No limitation & $\begin{array}{l}\text { No limitation, } \\
\text { unless it is the } \\
\text { primary purpose }\end{array}$ & $\begin{array}{l}\text { Obligatory; } \\
\text { No limitation }\end{array}$ & No limitation \\
\hline Objective & $\begin{array}{l}\text { Social, societal or } \\
\text { environmental } \\
\text { objective }\end{array}$ & $\begin{array}{l}\text { No restriction, } \\
\text { often serving a } \\
\text { dedicated } \\
\text { community }\end{array}$ & $\begin{array}{l}\text { Support the } \\
\text { economic } \\
\text { interests of its } \\
\text { members, but } \\
\text { objective may } \\
\text { also be broader if } \\
\text { specified in the } \\
\text { statute }\end{array}$ & $\begin{array}{l}\text { Administer and use } \\
\text { assets and } \\
\text { incomes only to } \\
\text { achieve } \\
\text { management of } \\
\text { assets to achieve } \\
\text { the social } \\
\text { objectives as } \\
\text { specified in the } \\
\text { statute }\end{array}$ & $\begin{array}{l}\text { Specified in the } \\
\text { articles } \\
\text { association }\end{array}$ & $\begin{array}{l}\text { The fully owned } \\
\text { subsidiary } \\
\text { transfers all } \\
\text { profits to the NGO } \\
\text { parent } \\
\text { organisation }\end{array}$ \\
\hline $\begin{array}{l}\text { Profit } \\
\text { distribution } \\
\text { criterion }\end{array}$ & $\begin{array}{l}\text { Limited profit } \\
\text { distribution/asset } \\
\text { lock }\end{array}$ & $\begin{array}{l}\text { Profit non- } \\
\text { distribution is } \\
\text { obligatory, } \\
\text { asset lock needs } \\
\text { to be specified in } \\
\text { the statute }\end{array}$ & $\begin{array}{l}\text { Specified in the } \\
\text { articles of } \\
\text { association, or } \\
\text { ad-hoc decided } \\
\text { by the General } \\
\text { Assembly }\end{array}$ & $\begin{array}{l}\text { Profit non- } \\
\text { distribution is } \\
\text { obligatory, } \\
\text { asset lock needs to } \\
\text { be specified in the } \\
\text { statute }\end{array}$ & $\begin{array}{l}\text { Specified in the } \\
\text { articles } \\
\text { association }\end{array}$ & $\begin{array}{l}\text { Rules for } \\
\text { associations and } \\
\text { companies apply } \\
\text { respectively }\end{array}$ \\
\hline $\begin{array}{l}\text { Governance } \\
\text { model }\end{array}$ & $\begin{array}{l}\text { Inclusive } \\
\text { governance }\end{array}$ & $\begin{array}{l}\text { Optional to have } \\
\text { civil society } \\
\text { organisations, } \\
\text { municipalities, } \\
\text { beneficiaries in } \\
\text { involved in } \\
\text { decision-making } \\
\text { General } \\
\text { Assembly } \\
\text { Decides }\end{array}$ & $\begin{array}{l}\text { General } \\
\text { Assembly } \\
\text { decides }\end{array}$ & $\begin{array}{l}\text { Council as } \\
\text { specified in the } \\
\text { statute decides }\end{array}$ & $\begin{array}{l}\text { Optional to have } \\
\text { civil society } \\
\text { organisations, } \\
\text { municipalities, } \\
\text { beneficiaries in } \\
\text { involved ision-making } \\
\text { decision }\end{array}$ & $\begin{array}{l}\text { Optional to have } \\
\text { civil society } \\
\text { organisations, } \\
\text { municipalities, } \\
\text { beneficiaries in } \\
\text { involved decision-making } \\
\text { decion }\end{array}$ \\
\hline Volunteers & $\begin{array}{l}\text { Engagement of } \\
\text { volunteers }\end{array}$ & Opportunity & Opportunity & Opportunity & $\begin{array}{l}\text { Not possible for } \\
\text { the regular } \\
\text { business } \\
\text { activities }\end{array}$ & $\begin{array}{l}\text { Rules for } \\
\text { associations and } \\
\text { companies apply } \\
\text { respectively }\end{array}$ \\
\hline $\begin{array}{l}\text { Accepts } \\
\text { donations }\end{array}$ & Yes & Opportunity & Opportunity & Opportunity & Not possible & $\begin{array}{lr}\text { Only } & \text { the } \\
\text { association } & \text { is } \\
\text { eligible } & \end{array}$ \\
\hline $\begin{array}{l}\text { Eligible for } \\
\text { NFCS funding }\end{array}$ & Eligible & Eligible & Eligible & Eligible & Not eligible & $\begin{array}{lr}\text { Only } & \text { the } \\
\text { association } & \text { is } \\
\text { eligible } & \end{array}$ \\
\hline $\begin{array}{l}\text { Eligible for } \\
\text { EASfunding }\end{array}$ & Eligible & Not eligible & Not eligible & Not eligible & Eligible & $\begin{array}{l}\text { Only the company } \\
\text { is eligible }\end{array}$ \\
\hline Tax exemption & Eligible & $\begin{array}{l}\text { Eligible, if } \\
\text { operating in the } \\
\text { public interest; or } \\
\text { for charitable } \\
\text { purposes }\end{array}$ & Not eligible & $\begin{array}{l}\text { Eligible, if operating } \\
\text { in the public } \\
\text { interest; or for } \\
\text { charitable } \\
\text { purposes }\end{array}$ & Not eligible & $\begin{array}{lr}\text { Only } & \text { the } \\
\text { association } & \text { is } \\
\text { eligible } & \end{array}$ \\
\hline $\begin{array}{l}\text { Main sources } \\
\text { of income }\end{array}$ & & $\begin{array}{l}\text { Trading, grants, } \\
\text { public contracts, } \\
\text { donations, } \\
\text { membership fees }\end{array}$ & Trading & $\begin{array}{l}\text { Trading, grants, } \\
\text { donations }\end{array}$ & $\begin{array}{l}\text { Trading, public } \\
\text { contracts }\end{array}$ & $\begin{array}{l}\text { NFCS grants, } \\
\text { public contracts, } \\
\text { donations (NGO } \\
\text { Trading, public } \\
\text { contracts, EAS } \\
\text { grants (company) }\end{array}$ \\
\hline $\begin{array}{l}\text { Administrative } \\
\text { costs }\end{array}$ & & $\begin{array}{l}\text { Comparatively } \\
\text { low }\end{array}$ & $\begin{array}{l}\text { Comparatively } \\
\text { low }\end{array}$ & $\begin{array}{l}\text { Comparatively high } \\
\text { (annual reviews) }\end{array}$ & $\begin{array}{l}\text { Comparatively } \\
\text { low }\end{array}$ & $\begin{array}{l}\text { Comparatively } \\
\text { higher }\end{array}$ \\
\hline VAT eligibility & & $\begin{array}{l}\text { If revenue is } \\
\text { higher than } \\
\text { EUR } 40000 \\
\text { annually } \\
\text { Advantage for } \\
\text { smaller } \\
\text { organisations }\end{array}$ & $\begin{array}{l}\text { If revenue is } \\
\text { higher than } \\
\text { EUR } 40000 \\
\text { annually } \\
\text { Advantage for } \\
\text { smaller } \\
\text { organisations }\end{array}$ & $\begin{array}{l}\text { If revenue is higher } \\
\text { than EUR } 40000 \\
\text { annually } \\
\text { Advantage for } \\
\text { smaller } \\
\text { organisations }\end{array}$ & $\begin{array}{l}\text { If revenue is } \\
\text { higher than } \\
\text { EUR } 40000 \\
\text { annually } \\
\text { Advantage for } \\
\text { smaller } \\
\text { organisations }\end{array}$ & $\begin{array}{l}\text { If revenue is } \\
\text { higher than } \\
\text { EUR } 40000 \\
\text { annually for each } \\
\text { organisation } \\
\text { Advantage for } \\
\text { smaller } \\
\text { organisations }\end{array}$ \\
\hline
\end{tabular}


74

\begin{tabular}{llllll}
\hline $\begin{array}{l}\text { Empirical } \\
\text { observations }\end{array}$ & $\begin{array}{l}\text { Most } \\
\text { form }\end{array}$ & common & $\begin{array}{l}\text { Exceptionally } \\
\text { used }\end{array}$ & A few & $\begin{array}{l}\text { Numbers } \\
\text { increasing }\end{array}$ \\
\hline
\end{tabular}

Source: OECD elaboration based on the study visit and institutional websites including: https://www.riigiteataja.ee/en/eli/515012018007/consolide

https://www.riigiteataja.ee/en/eli/516112017003/consolide

https://www.riigiteataja.ee/en/eli/519122017001/consolide 
More information: www.oecd.org/cfe/leed/

Follow us on Twitter: OECD SMEs, Regions, Cities

@oECD_local

9) OECD 